\title{
LUCIS Modeliyle Tekirdağ Şehrinin Yerleşme Uygunluk Analizi*
}

\section{Settlement Suitability Analysis of the Tekirdağ City Using the LUCIS Model}

\author{
Müjde AYDOĞDU ${ }^{1}$ (D), Muzaffer BAKIRCI² \\ ${ }^{1}$ Doktora Öğrencisi, İstanbul Üniversitesi, Sosyal Bilimler Enstitüsü Coğrafya Anabilim Dalı, İstanbul, Türkiye \\ ${ }^{2}$ Doç. Dr. İstanbul Üniversitesi, Edebiyat Fakültesi Coğrafya Bölümü, İstanbul, Türkiye
}

ORCID: M.A. 0000-0002-1452-7730; M.B. 0000-0002-4848-3086

\section{öz}

Şehirlerin yer seçiminde ve gelişme akslarının belirlenmesinde bilimsel veriler kullanarak, uygunluk analizleri yapmak ve ileriye dönük modeller oluşturmak, şehirlerin doğal çevre ile uyum içerisinde büyümesine katkı sağlamakta ve sürdürülebilir şehirsel alanları ortaya çıkarmaktadır. Son yıllarda şehirsel yer seçimine yönelik yoğun şekilde kullanılan uygunluk analizleri, şehirlerin büyümesini daha kontrollü hale getirerek yerleşim için en uygun yerleri tespit etme fırsatı sunmaktadır. Bu çalışmada, yer seçimi uygunluk analizlerinde yeni bir yöntem olan LUCIS (Land Use Conflict Identification Strategy) modeliyle Tekirdağ şehrinin yerleşime uygunluğu incelenmiştir. Çalışma kapsamında, öncelikle yöntem esasına uygun bir biçimde Tekirdağ şehrinde yerleşim alanlarını etkileyecek doğal ve beşeri faktörlere ait birçok alt amaç, amaç ve bunlara bağlı genel amaçlar belirlenmiş, veri katmanları hazırlanmış, model oluşturulmuş ve son olarak da uygunluk analizi yapılmıştır. Elde edilen değerler atanan ağırlıklara göre birleştirilerek, Tekirdağ şehrinin yer seçimi açısından konut, ticaret ve sanayi yerleşimine uygunluk düzeyleri ve bu uygunlukların çalışma alanındaki dağılımları değerlendirilmiştir. Yapılan analizler sonucunda, çalışma sahasının konut yerleşimi açısından \%24,26'sının yüksek uygunlukta, ticari üniteler açısından \%50,19'unun düşük uygunlukta, sanayi birimleri için ise \%47,36'sının orta uygunlukta olduğu tespit edilmiştir. Konut, ticaret ve sanayi alanları birlikte değerlendirildiğinde ise Tekirdağ şehrinin \%19,80'inin yerleşim açısından yüksek uygunlukta olduğu belirlenmiştir.

Anahtar kelimeler: LUCIS Modeli, Tekirdağ Şehri, Uygunluk Analizi

\section{ABSTRACT}

Conducting a conformity analysis helps minimize damages due to natural disasters that may occur in a city and contributes to the growth of the city in harmony with the environment. Moreover, it offers an opportunity to identify the most suitable locations for settlement by making the growth of cities increasingly controlled. In this study, the suitability of the Tekirdağ city in terms of settlement was examined using the land-use conflict identification strategy model. In this context, many subgoals, objectives, and general purposes related to physical and human factors that can affect the settlement areas in the Tekirdağ city are determined, and a conformity analysis is conducted. Combining the obtained outputs according to the assigned weights, the suitability levels of the Tekirdağ city for residential, commercial, and industrial settlement were evaluated. According to the analysis, $24.26 \%$ of the work area is of high suitability for residential settlements, $50.19 \%$ is of low suitability for commercial units, and $47.36 \%$ is of medium suitability for industrial units. When the residential, commercial, and industrial areas were evaluated together, it was revealed that $19.80 \%$ of the Tekirdağ city was highly suitable for settlement.

Keywords: LUCIS Model, Tekirdağ City, Suitability Analysis

*Bu çalışma, İstanbul Üniversitesi Sosyal Bilimler Enstitüsü’nde yürütülen "LUCIS Modeliyle Tekirdağ Şehrinin Mekansal Kullanım ve Gelişim Analizi" başlıklı doktora tezinden üretilmiştir.

Başvuru/Submitted: 22.10.2020 • Revizyon Talebi/Revision Requested: 15.01.2021 • Son Revizyon/Last Revision Received: 07.03 .2021 • Kabul/Accepted: 31.03 .2021

Sorumlu yazar/Corresponding author: Müjde AYDOĞDU / mujde.5758@gmail.com Atıf/Citation: Aydogdu, M., \& Bakirci, M. (2021). LUCIS modeliyle Tekirdağ şehrinin yerleşme uygunluk analizi. Cografya Dergisi, $42,67-84$. https://doi.org/10.26650/JGEOG2020-814846 


\section{EXTENDED ABSTRACT}

Change in space that started with the settled life of people has reached much greater dimensions with the development of technology in the last 50 years. Cities have an important place in human settlement and are the most affected by this change.

When changes in the environment occur in an uncontrolled manner, irreversible damages are experienced. Determining the most suitable place for settlement in a space, examining its suitability for the direction of urban development, and making progressive predictions help minimize damages. The land-use conflict 1dentification strategy (LUCIS) model that aids compliance analysis is developed in 2007, is a purpose-based model, and the objectives are established in a hierarchical and logical order. This hierarchical structure that develops from general goals to subgoals includes many sequential goals. The category purpose is to determine suitable settlement areas and consists of three general goals, six goals, and 37 subgoals.

In this study, the settlement suitability analysis of the Tekirdağ city has been made in terms of human and physical factors. Based on the LUCIS model parameters, according to the results of the analysis conducted, 24.26\% (4336.96 hectares) of the study area is highly suitable according to YGA1, in which suitable areas for residential settlement are analyzed. These areas, where the most suitable residential settlements are seen according to all the physical and human factors, are concentrated in the south of the study area along the center and coast. In the north of the study area, where high suitability turns into medium suitability, suitability is gathered at certain points. From the study area, 41.20\% (7363.56 ha.) consists of medium suitability areas in terms of housing settlement. These areas, observed particularly in the middle parts and close vicinity of the areas with high suitability, are scattered throughout the study area.

According to YGA2, in which suitable areas for trade settlement are determined, half of the working area (50.19\%) is of low suitability. As observed in the residential settlements, the areas that are generally seen in the northern parts of the commercial settlements are concentrated in the places where streams, stream branches, and agricultural areas are located. High-suitability areas, covering 3276.13 hectares, constitute $18.33 \%$ of the total area. Especially, such areas that are concentrated in the south of the study area decrease as they move away from the center and transportation networks and turn into low suitability areas in the north.

According to YGA3, in which suitable areas for industrial settlements are determined, 8465.00 hectares (47.36\%) of the study area is medium suitable. These areas, spread throughout the study area, are mostly seen in the intersection regions with high-suitability areas around the streams. Especially, because of the possibility of flooding in the stream beds and necessity to prevent the pollution of the waters, the places with low conformity (22.33\% and 3990.78 hectares) are accompanied by the concentration of the stream beds.

According to the results of the YKA analysis, in which three general purposes of settlement (YGA1, YGA2, and YGA3) are combined in a single category, 3539.87 hectares of the study area are highly suitable for settlement. Covering $19.80 \%$ of the total area, the highsuitability areas are mostly concentrated in the south, southwest, and southeast parts of the study area, in the neighborhoods of Gazioglu Köseilyas, Kayı, and Yağcı. These are old village settlements in the north but have become a neighborhood of the Tekirdağ city.

In the study area, the areas with low suitability for YKA cover 7668.40 hectares and constitute $42.90 \%$ of the total area. These areas, concentrated in the stream, stream beds, and their close surroundings, can be seen in almost all the northern part of the study area.

According to the results of the YKA analysis, in which the purpose of the settlement category was analyzed, the medium suitability areas, covering 6665.84 hectares in the study area, constituted $37.29 \%$ of the total area. These areas, concentrated in the north, middle, and close to transportation networks, constitute the second-most suitable areas in terms of settlement after the high-suitability areas.

As a result, in this study, although it is unpredictable when the Tekirdağ city will attain the image obtained via the YKA analysis, the place where the current city settlement is established is suitable with respect to physical and human factors. Considering the results of the YKA analysis, the Köseilyas and Kayı neighborhoods in the northeast of the study area have started to form an uninterrupted connection with the center of the Tekirdağ city, and this region has high and medium suitability. It is thought that the development of the city will shift toward this region in the future, or it will be highly correct to have the settlement areas that are likely to be opened. 


\section{GíRIŞ}

Coğrafya, yeryüzündeki olaylar arasındaki ilişkileri, bu olayların dağılışını ve bu dağılışının nedenlerini inceleyen bir bilim dalıdır (Tanoğlu, 1964: 3). Dolayısıyla Coğrafya bilimi, mekânı insanla birlikte değerlendirerek, mekânın insan üzerindeki, insanın da mekân üzerindeki etkilerini gözlemleyip, analiz ederek elde edilen sonuçları sentez olarak sunmaktır (Özçağlar, 2014: 2). Mekân kavramı Arapça "kevn" yani olmak kökünden türeyen bir kelimedir. Genellikle "yer" anlamında kullanılmakla birlikte içinde bulunulan çevre, ortam, yaşanan dünya ve kâinat anlamlarını da içermektedir (Göka, 2001: 8). İnsanlığın yerleşik hayata geçmesiyle önem kazanan mekân olgusu, her ne kadar coğrafi bir yer algısı üzerine tartışılmaya başlanmışsa da süreç içerisinde "yaşam alanı" olarak anılmıştır. Tarih boyunca mağaralardan metropollere uzanan bu süreçte temel amaç insanın barınma ihtiyacının giderilmesidir. Bu ihtiyacın karşılanması için birinci şart ise yer seçimidir. Yerleşmenin doğuşu, birden fazla sayıda aile bireylerinin bir araya gelmesi ve yerleşilecek yerin seçimi ile başlamaktadır (Tunçdilek, 1986: 5). Yerleşme sistematiğinin iki temel unsurundan biri olan şehirler, medeniyetlerin merkezleridir ve yerleşme coğrafyası içerisinde önemli çalışma alanlarından birini oluşturmaktadır (Ceylan ve Demir, 2020).

Türkiye'nin kuzeybatısındaki Trakya Yarımadasında yer alan Tekirdağ şehri (Harita 1) coğrafi konumu, çevresindeki verimli tarım arazileri, rahat ulaşım şartları ve mevcut limanı sayesinde tarihin her döneminde önemli bir yerleşme yeri olarak ön plana çıkmıştır.

Tekirdağ şehrinin geçmişten günümüze çeşitli yönleriyle bilimsel çalışmalara konu olduğu görülmektedir. Tolun Denker 1973 yılında yazdığ 1 "Tekirdağ şehir nüfusu” adlı makalesinde şehrin nüfusunun yapısını, aldığı göçleri, dağılışını ve yoğunluğunu mahalle düzeyinde ele alarak detaylı bir şekilde incelemiştir. Özşahin 2014 yılında yayınladığı “CBS kullanılarak şehir ve jeomorfoloji arasındaki ilişkinin incelenmesi: Tekirdağ şehri örneği” adlı makalesinde, Tekirdağ şehrinin jeomorfolojik birimlerini tespit etmiş ve bu birimlerin şehirsel alanla olan ilişkisini ortaya koymuştur. Yine Özşahin 2015 yılında yayınladığı "Şehir ve toprak arasındaki ilişkinin coğrafi yaklaşımla incelenmesi: Tekirdağ şehri örneği” adlı çalışmasında Tekirdă̆ şehrinin günümüz gelişim sahasındaki toprak özelliklerini coğrafi yaklaşımla incelemiştir. Özşahin ve arkadaşları tarafindan 2016 yılında hazırlanan "Tekirdağ şehri ve yakın çevresinde arazi kullanımının zamansal ve mekânsal değişimi” adlı makalede, Tekirdağ şehri ve yakın çevresinin 1900 ve 2015 yıllarına ait arazi kullanım haritaları oluşturulmuş, belirlenen arazi kullanım sınıfları değişim yönü yöntemiyle analiz edilmiş ve zamansal farklılaşmanın yönü ortaya konulmuştur. Siyavuş 2019 yılında hazırladığg "Tekirdağ şehir coğrafyası” başlıklı doktora tezinde, Tekirdağ şehrinin kuruluş

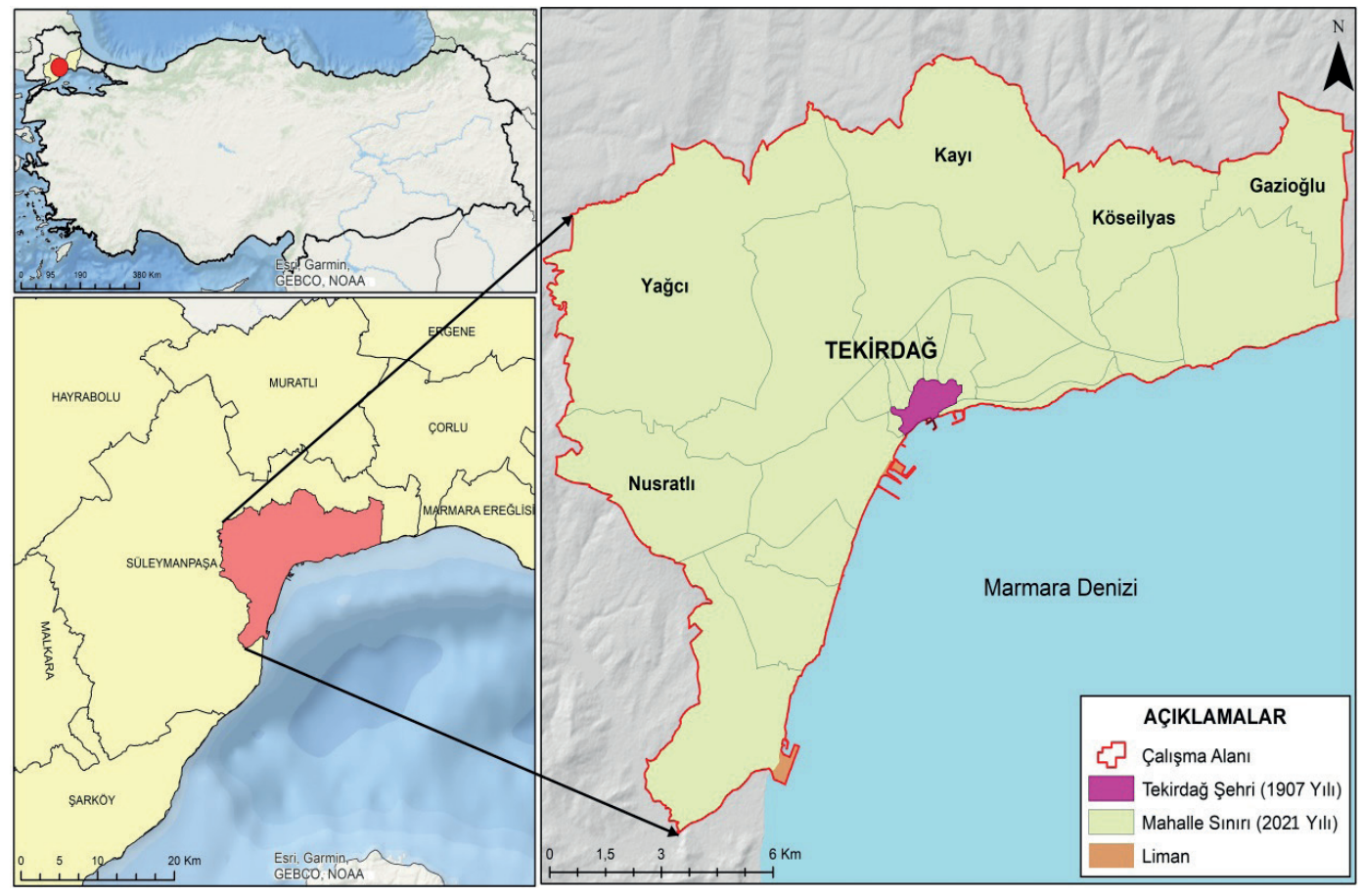

Harita 1: Çalışma Alanının Lokasyon Haritası.

Map 1: Location Map of the Study Area. 
ve gelişiminde etkili olan fiziki ve beşerî unsurları, nüfus ve yerleşme özellikleri ile şehrin fonksiyonel özelliklerini ortaya koymuş, şehirde mevcut ve muhtemel sorunlara yönelik çözüm önerileri sunmuştur. Tarafımızca hazırlanan bu çalışma, yukarıda belirtilen çalışmaların içeriklerini de kısmet kapsamakla birlikte, LUCIS modeliyle Tekirdağ şehrinin doğal ve beşeri çevre özellikleri açısından yerleşime uygunluğunu analiz etmesi açısından farklılaşmaktadır. Bu çalışmada sadece Tekirdağ şehrinin mevcut konut, ticaret ve sanayi yerleşime uygunluğu incelenmekle yetinilmemiş, aynı zamanda gelecek için şehrin coğrafi açıdan yerleşime uygun alanları da belirlenmiştir.

Doğal çevre, insanlar tarafindan değişik şekillerde değerlendirilmekte ve buna bağlı olarak da arazi örtüsü ve kullanımında zaman içerisinde önemli değişiklikler meydana gelmektedir. İnsanoğlunun yerleşik hayata geçmesiyle başlayan ve gün geçtikçe daha da büyüyen bu değişiklikler, günümüzde teknolojinin gelişmesiyle çok daha büyük boyutlara ulaşmış durumdadır.

İnsanın doğaya müdahalesi sonucu yeryüzünde oluşan tahribatlar, insan ve doğa arasındaki ilişkiyi yeniden irdelemeyi gerektirmektedir. Bu ilişkiyi detaylı bir şekilde inceleyip, gelecek arazi kullanımları için alternatifler önermede başvurulan yöntemlerden biri uygunluk analizleridir (Steiner, 2000: 54). Uygunluk analizleri; incelenen bir alanın tüm doğal ve yapay öğelerini farklı analiz katmanları olarak ele alıp üst üste çakıştırarak, alanın bir veya birden fazla işleve uygunluğunu değerlendirmeyi amaçlamaktadır (Özügül, 2004: 55). $\mathrm{Bu}$ kapsamda, yerleşim yeri seçimi ve yerleşime uygunluk gibi konuların bilimsel çalışmalara sıç̧a konu olduğu görülmektedir (Aydöner ve Maktav, 2013; Winterbach vd., 2014; Kurnaz ve Ramazanoğlu, 2014; Çavuş ve Koç, 2015; Kavurmacı, 2016; Buzai \& Principi, 2017; Huang vd. 2019). Belirtilen amaca hizmet eden yöntemlerden biri olan LUCIS modeli uygunluk analizleri için yeni araçlar sunmakta ve gelecekte görülmesi muhtemel alan kullanım uyuşmazlıklarını mekânsal olarak ortaya koymaktadır (Nayim, 2014; Taşdemir ve Kaya, 2015). Bu çalışmada, mekânsal olarak hızlı büyüyen ve kalabalıklaşan Tekirdağ şehrinde karşılaşılan problemlerin çözümüne yardımcı olabilecek bir yöntem olan LUCIS modeli ile yerleşime uygunluk analizi yapılmıştır. Böylece Tekirdağ şehrinin mevcut arazi kullanımının yerleşme açısından uygunlukları ortaya konularak çıkan sonuçlar coğrafi perspektifte neden-sonuç ilişkisi kurularak değerlendirilmiştir.

\section{AMAÇ VE YÖNTEM}

Uygunluk analizleri, planlamaya yönelik gerçekleştirilen envanter ve analiz çalışmalarından elde edilen bilgilerin, alanın sorunlarına yönelik oluşturulan amaçları ilişkilendirme firsatı sunduğu için (McHarg, 1992) çeşitli alan kullanımları tespitinde sıklıkla tercih edilen bir yöntemdir. Temel amacı Tekirdağ şehrinin yerleşim yeri açısından doğal ve beşeri unsurlara uygun olup olmadığını analiz etmek olan bu çalışmanın yöntemini LUCIS (Land Use Conflict Identification Strategy) modeli oluşturmaktadır. Model kullanıcılarına mevcut yerleşim, koruma ve tarım alanlarını belirleyebilme firsatı sağladığı gibi, geleceğe yönelik tüm kategorilerin tercih edilen alanları belirleyebilme ve gelecekte uyuşmazlık yaşanması muhtemel alanları tespit edebilme imkânı da sunmaktadır. Tüm bu tespitleri aynı anda yapabilmesi, bunu istatistiki ve görsel olarak desteklemesi modeli daha kullanılır yapmaktadır. Sayılan avantajlı özellikleri, çalışmamızda LUCIS modelinin tercih edilmesine zemin hazırlamıştır.

Belirtilen model raster tabanlı bir model olduğundan uygunluk analizlerinde kullanılan tüm veriler raster verilere dönüştürülmüştür. Raster verinin piksel boyutu analizlerde oldukça önemlidir. LUCIS modelinin ilk uygulandığ Florida örneğinde Carr ve Zwick (2007) piksel büyüklüğünü 62 m x 62 m, Bartın örneğinde Nayim (2011) piksel büyüklüğünü $25 \mathrm{~m} \mathrm{x}$ $25 \mathrm{~m}$, Taşdemir (2017) ise $30 \mathrm{~m}$ x $30 \mathrm{~m}$ olarak seçmiştir. Çalışmada piksel boyutu belirlenirken çalışma alanının büyüklüğü, kullanılan verilerin çözünürlüğü, ulaşılması istenen sonuç gibi birçok faktör göz önünde bulundurularak bu çalışmada piksel boyutu $15 \mathrm{~m}$ x $15 \mathrm{~m}$ olarak belirlenmiştir. Analizlerde kullanılan tüm veriler (Tablo 1) analizlere uygun hale

Tablo 1: Çalışmada Kullanılan Veri Setleri. Table 1: Data Sets Used in the Study.

\begin{tabular}{lcc}
\hline Kullanılan Veri Setleri & Türü & Veri Kaynağı \\
\hline Topografya (1/25.000) & Raster & HGM \\
Jeoloji & Vektör & MTA \\
Eğim & Raster & DEM \\
Heyelan & Vektör & MTA \\
Konut alanları & Vektör & İmar planı, ÇDP vd. \\
Eğitim kurumları & Vektör & Imar planı, ÇDP vd. \\
Sağlık kurumları & Vektör & İmar planı, ÇDP vd. \\
İari kurumlar & Vektör & Imar planı, ÇDP vd. \\
Sanayi alanları & Vektör & İmar planı, ÇDP vd. \\
Ticaret alanları & Vektör & İmar planı, ÇDP vd. \\
Parklar ve dinlenme alanları & Vektör & İmar planı, ÇDP vd. \\
Tarihi ve kültürel alanlar & Vektör & İmar planı, ÇDP vd. \\
Atıksu arıtma tesisi & Vektör & İmar planı, ÇDP vd. \\
Dere, göl ve gölet & Vektör & Topografya (1/25.000) \\
Liman ve iskele & Vektör & İmar planı, ÇDP vd. \\
Fay hatları & Vektör & MTA \\
Boru hatları & Vektör & BOTAŞ \\
Demiryolu & Vektör & TCDD \\
Karayolu & Vektör & KGM \\
Uydu görüntüleri (2010, 2020) & Raster & https://www.usgs.gov/ \\
DEM & Raster & https://asf.alaska.edu/ \\
Kadastro verisi & Vektör & Tekirdağ Büyükşehir Belediyesi \\
Nazım imar planı & Vektör & Tekirdağ Büyükşehir Belediyesi \\
Çevre düzeni planı (ÇDP) & Raster & Tekirdağ Büyükşehir Belediyesi \\
\hline & &
\end{tabular}


getirilmiştir. ArcGIS yazılımının ModelBuilder arayüzünü kullanan LUCIS modeli raster tabanlı bir model olduğu için kullanılan tüm vektör veriler yukarıda belirtilen piksel boyutuna göre $(15 \mathrm{~m} \mathrm{x} 15 \mathrm{~m})$ raster hale dönüştürülmüsştür.

Amaç tabanlı bir model olan LUCIS'de, amaçlar hiyerarşik ve mantıklı bir sıra ile oluşturulmaktadır. Genel amaçlardan alt amaçlara doğru gelişen bu hiyerarşik yapı alt alta birçok amacı kapsamaktadır (Şekil 1). Bu hiyerarşik sıra yukarıdan aşağıya doğru sıralanmasına rağmen modelin işleyişi en alt düzeyden yukarıya doğrudur. Yani ilk olarak alt amaçlara ait analizler yapılmakta, sonra alt amaçlar birlikte değerlendirilip amaçlara ait sonuçlar elde edilmekte, ardından amaçlara ait sonuçlar birlikte değerlendirilerek genel amaçlara ve sonunda en üst düzeye, yani kategoriye (yerleşime uygunluk) ait sonuçlara ulaşılmaktadır.

LUCIS modelinde kullanılan amaçlara ait akış şeması 4 aşamadan oluşmakta, bu kategorilerin en üstünde kategori amacı

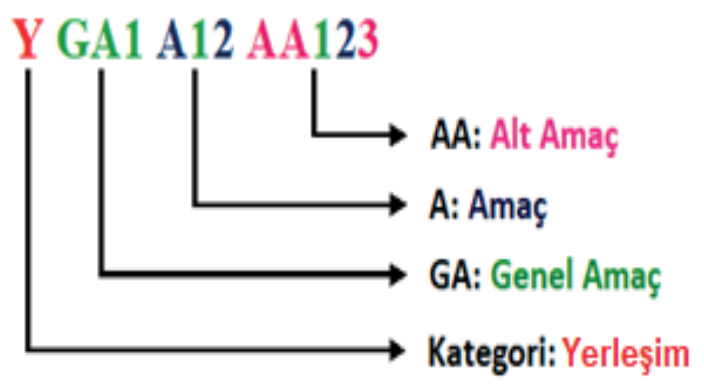

Şekil 2: LUCIS'de Kullanılan Örnek Bir Model Kodlama. Figure 2: A Sample Coding Model Used in LUCIS. yer almaktadır. Bunu sırasıyla genel amaçlar, amaçlar ve alt amaçlar takip etmektedir. Söz konusu amaçlar belli bir kodlama ile yapılmaktadır. Kategorilere ve amaç hiyerarşisine göre hazırlanan her kod bir amac1 temsil etmektedir. Örneğin, YGA1A12AA123 kodu yerleşim kategorisinin 1. genel amac1 (GA) altındaki 2. amacın (A), 3. alt amacına (AA) aittir (Şekil 2).

Karışıklı̆̆ kategorisine ait amaçların her birine kendine ait bir kod verilmektedir. Yerleşim kategorisi içerisinde kullanılan tüm amaçlar ve bunlara ait kodlar Şekil 3 'te gösterildiği şekildedir.

\section{BULGULAR}

Yerleşim için uygun alanlarının belirlenmesi olan kategori amacı; 3 genel amaç, 6 amaç ve 37 alt amaçtan oluşmaktadır. Tüm yerleşim birimlerini içerisine alan Yerleşim Kategori Amacı (YKA) alt amaçlardan amaçlara doğru hiyerarşik bir yapı göstermekte ve tüm amaçlara ait uygunluk analizleri ve çıktılarından oluşmaktadır. Burada alt amaçlara ait yapılan uygunluk analizleri ve bunlara ait çıktılar çok fazla yer kaplayacağ 1 için sadece amaçlar, genel amaçlar ve kategori amacı ile bunların analizinde kullanılan veriler, elde edilen çıktılar verilebilmiştir.

\subsection{YGA1: Konut için uygun alanların belirlenmesi}

Yerleşim kategorisi içerisindeki 3 genel amaçtan biri olan ve uygun konut alanlarının belirlenmesinde kullanılan YGA1, doğal ve beşeri olmak üzere 2 amaç ve 13 alt amaçtan oluşmaktadır.

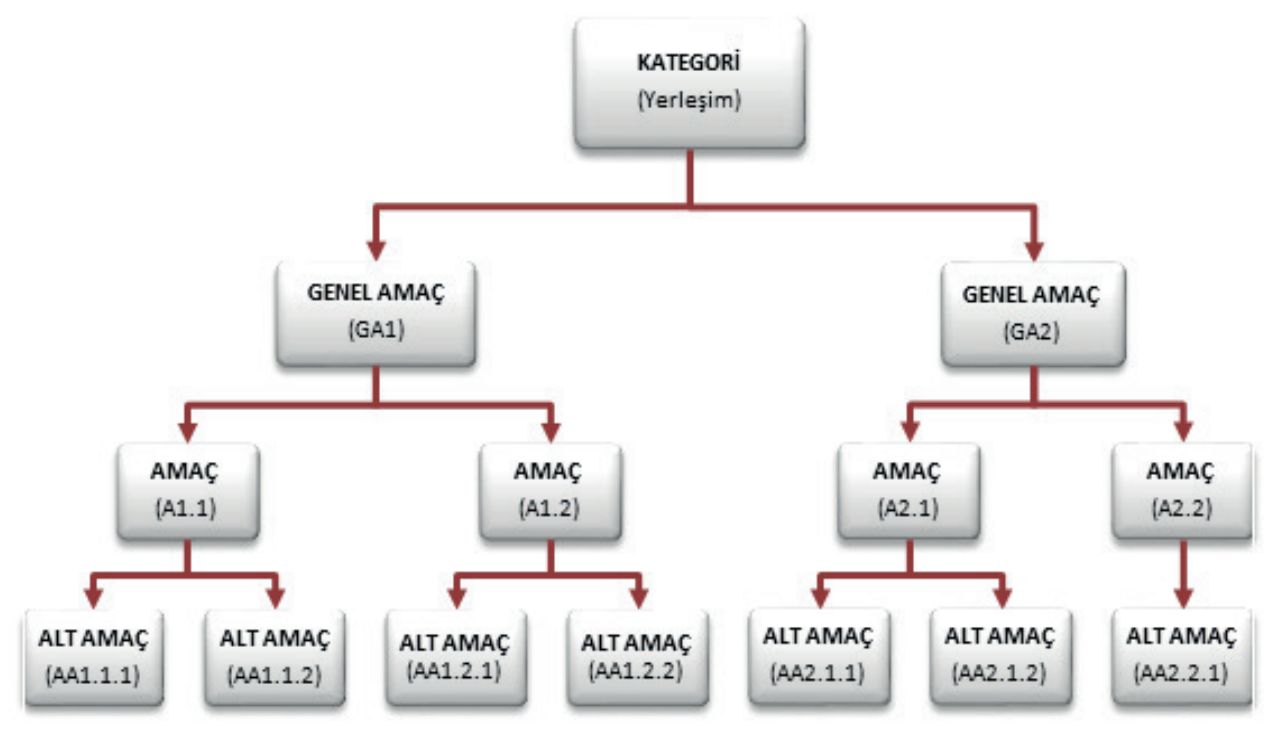

Şekil 1: LUCIS Modelinde Kullanılan Amaçlara Ait Hiyerarşik Yapı (Carr ve Zwick, 2007'den faydalanılarak üretilmiştir.)

Figure 1: Hierarchical Structure for the Purposes Used in the LUCIS Model. 


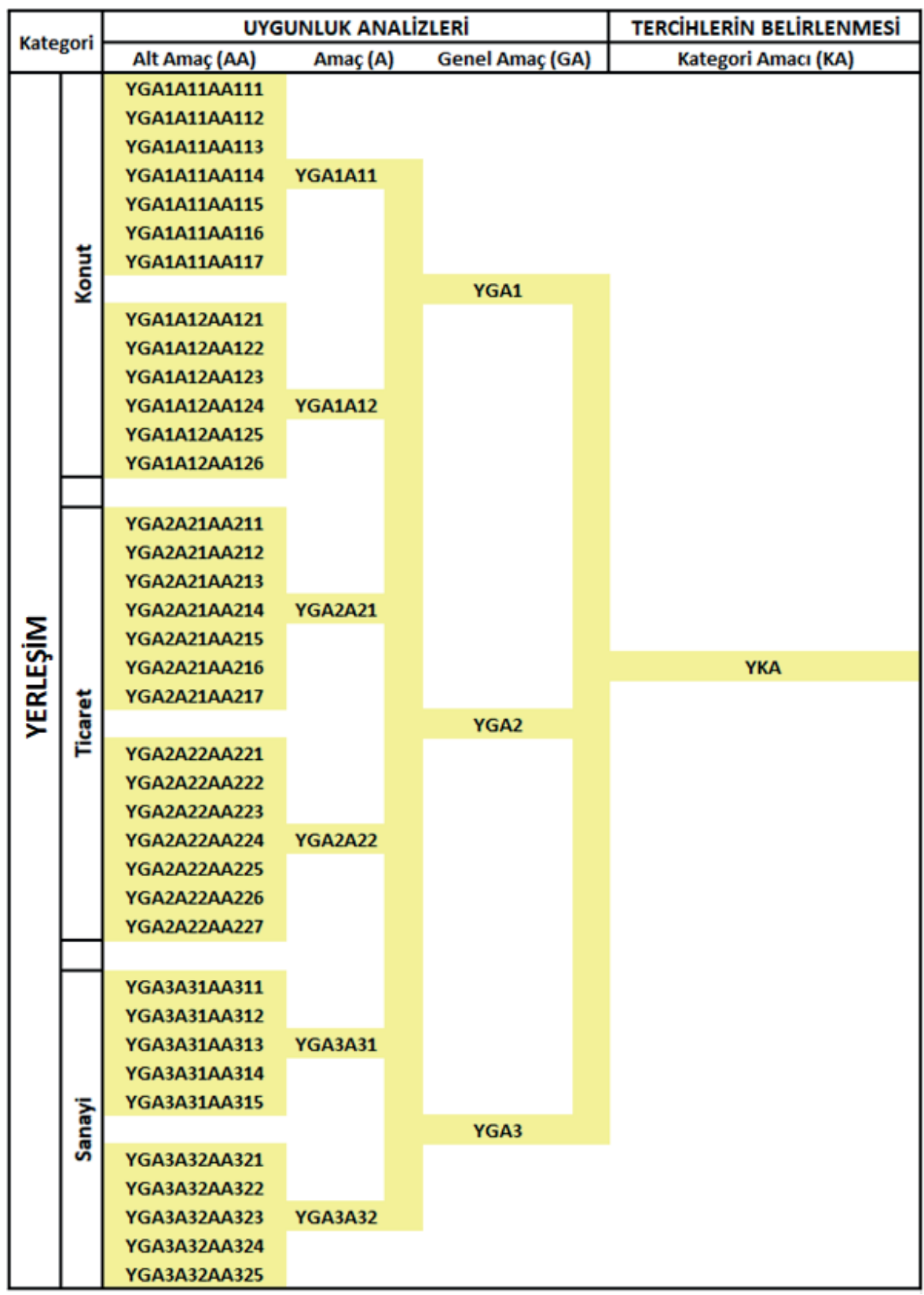

Şekil 3: Yerleşim Kategorisi İçin Kullanılan Tüm Amaçlar ve Kodları.

Figure 3: All Purposes and Codes Used for the Settlement Category.

3.1.1. YGA1A11: Doğal çevre özellikleri bakımdan uygun konut alanlarının belirlenmesi

Doğal çevre özellikleri açısından konut yerleşimine uygun alanların belirlendiği YGA1A11 amaç analizinde 7 alt amaç kullanılmıştır (Tablo 2).

Değer atama gerekçesi: Analizler için sel riski verisine konut alanlarına uygun yerlerin belirlenmesi bakımından yüksek değer verilmiştir. Bunun en önemli nedeni sel ve taşkınlar
Tablo 2: YGA1A11 Amacında Kullanılan Veriler ve Değer Atama Kriterleri. Table 2: Data and Value Assignment Criteria Used for YGA1A11 Purpose.

\begin{tabular}{cclc}
\hline \multirow{2}{*}{ Sıra } & \multicolumn{2}{c}{ Kullanılan Veriler } & Değer Atama Kriteri \\
\cline { 2 - 4 } & \multicolumn{1}{c}{ Kod } & \multicolumn{1}{c}{ Alt Amaç } & Oran (\%) \\
\hline 1 & YGA1A11AA111 & Sel riski & 40 \\
2 & YGA1A11AA112 & Eğim & 10 \\
3 & YGA1A11AA113 & Gürültü ve hava kirliliği & 5 \\
4 & YGA1A11AA114 & Zemin özellikleri & 10 \\
5 & YGA1A11AA115 & Deprem ve heyelan riski & 15 \\
6 & YGA1A11AA116 & Atıksu arıtma tesisi & 5 \\
7 & YGA1A11AA117 & Tehlikeli alanlar (yüksek & 15 \\
& & gerilim, boru hatları vs.) & \\
\hline
\end{tabular}


meydana geliş sıklığı, etkilediği alanın büyüklüğü, mevcut yapılaşma durumu ve ortaya çıkardı̆̆ı zararlar bakımından dünya üzerinde en fazla etkiye sahip doğal afetlerden biri olmasıdır (Dutta vd., 2006). Ayrıca Tekirdağ şehrinde yakın geçmişte (1997, 1998, 2007 ve 2012 yıllarında) yılda bir, birkaç yılda bir veya yılda iki kez sel ve taşkın olayları yaşandığı için (Turan, 2008: 247; Bağdatl1, 2013: 143) verilen değerlerde buna da dikkat edilmiştir. Aynı şekilde heyelan alanları ve boru hatlarının geçtiği yerler de sağlık ve güvenlik açısından konut alanlarını diğer analizlere göre daha fazla etkileyeceği değerlendirildiğinden \%15 ağırlık verilerek birleştirilmiştir.

Analizin yorumlanması: Analiz sonucunda, özellikle dere yatakları ve heyelan bölgelerinin konut yerleşimi açısından düşük uygunlukta (\%15,56-2625,10 ha.) olduğu tespit edilmiştir. Çalışma alanının \%45,55'i (8142,13 ha.) doğal çevre özellikleri açısından konut alanlarına orta uygunlukta, \%39,76's1 (7106,88 ha.) ise yüksek uygunlukta olduğu saptanmıştır (Harita 2). Özellikle Tekirdağ şehrinin merkezini oluşturan ve Ceyport limanının kuzey ve batı kısımlarını içine alan kesimler doğal çevre özellikleri açısından konut yerleşimine yüksek uygunlukta çıkan yerler arasındadır. Bu durum Tekirdağ şehrinin ilk kurulduğu yerin doğal çevre özellikleri açısından konut yerleşimine uygun olduğunu ve insanların buraya yerleşirken doğal unsurları göz ardı etmediğini göstermektedir.
3.1.2. YGA1A12: Beşeri çevre özellikleri bakımdan uygun konut alanların belirlenmesi

Beşeri çevre özellikleri açısından konut yerleşimine uygun alanların belirlendiği YGA1A12 amaç analizinde 6 alt amaç kullanılmıştır (Tablo 3).

Tablo 3: YGA1A12 Amacında Kullanılan Veriler ve Değer Atama Kriterleri. Table 3: Data and Value Assignment Criteria Used for YGA1A12 Purpose.

\begin{tabular}{llll}
\hline \multirow{2}{*}{ sıra } & \multicolumn{2}{l}{ Kullanılan Veriler } & Değer Atama Kriteri \\
\cline { 2 - 4 } & Kod & Alt Amaç & Oran (\%) \\
\hline 1 & YGA1A12AA121 & Mevcut konutlar & 25 \\
2 & YGA1A12AA122 & Hastane ve sağlık kurumları & 15 \\
3 & YGA1A12AA123 & Eğitim kurumları & 15 \\
4 & YGA1A12AA124 & $\begin{array}{l}\text { Idari kurumlar (kaymakamlık, } \\
\text { belediye binası vd.) }\end{array}$ \\
5 & YGA1A12AA125 & $\begin{array}{l}\text { Parklar, tarihi mekanlar ve } \\
\text { diğer rekreasyon alanları }\end{array}$ & 15 \\
6 & YGA1A12AA126 & Ulaşım ağları & 15 \\
\hline
\end{tabular}

Değer atama gerekçesi: Beşeri çevre özellikleri bakımdan uygun konut alanlarına ait en yüksek değer \%25 ile mevcut konut yerleşimlerinin analiz edildiği YGA1A12AA121'e ait alt amaca verilmiştir. Bir yerde mevcut konut varsa oranın yerleşim için daha uygun olacağı düşünülmüş ve yeni yapılacak konutları kendine çekeceği varsayılmıştır. YGA1A12AA122YGA1A12AA126 arasındaki analizlere ise eşit şekilde ağırlık

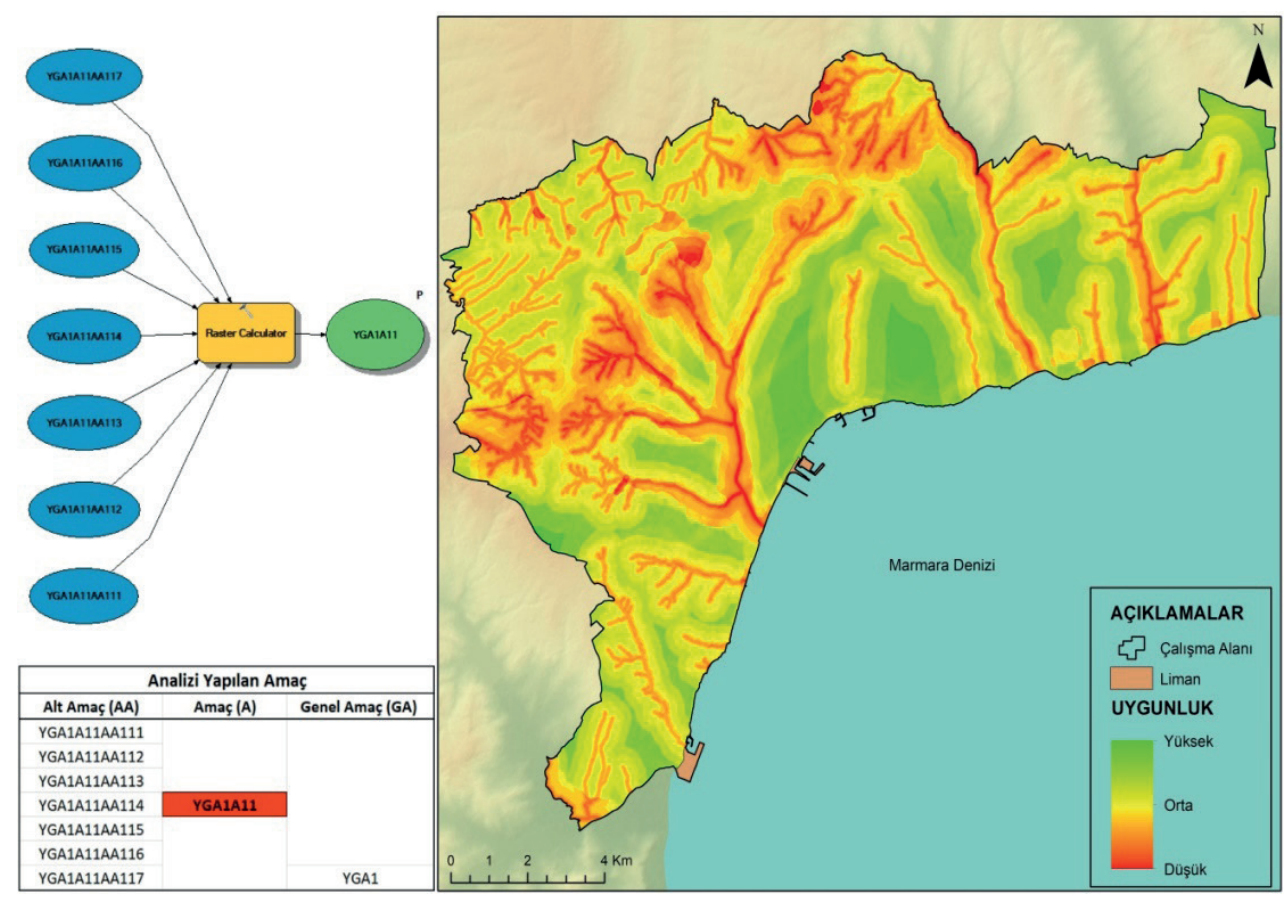

Harita 2: YGA1A11- Doğal Çevre Özellikleri Bakımdan Konut Yerleşim Alanları Uygunluk Analizi. Map 2: YGA1A11- Physical Conformity Analysis for Residential Settlements. 
(\%15) verilmiştir. Bunun nedeni ise diğer tüm alt amaçların yerleşim üzerinde aynı oranda etkili olacağının düşünülmesidir.

Analizin yorumlanması: YGA1A12 analiz sonucunda çalışma alanının güney kısımlarının yüksek uygunlukta kuzeye gittikçe orta ve düşük uygunlukta olduğu görülmektedir (Harita 3). Analiz sonucu, çalışma alanının 9273,64 hektarı $(\% 51,88)$ düşük uygunlukta çıkarken, 4814,18 hektarının $(\% 26,93)$ orta uygunlukta olduğu tespit edilmiştir.

Çalışma alanının \%21,18 beşeri çevre özellikleri bakımdan konut alanları için yüksek uygunlukta çıkmıştır. Özellikle çalışma alanının güneyinde yoğunlaşan bu alanlar kuzeye gittikçe belli bölgelerde toplanmakta, kuzeyde tamamen ortadan kalkmaktadır. Ulaşım ağlarının geçtiği güzergâhlar, kamu ve diğer resmi kurumlara yakın olan yerler konut yerleşimi açısından orta uygunlukta çıkan yerler olmuştur. $\mathrm{Bu}$ alanlar yüksek uygunluk ile düşük uygunluk görülen alanların kesiştiği yerlerde özellikle çalışma alanının orta kısmında yoğunlaşmaktadır (Harita 3).

Özellikle çalışma alanının kuzeyinde uygunluğun belirli yerlerde yoğunlaşması diğer yerlerin ise düşük uygunlukta çıkması buraların tarım alanı olmasından kaynaklanmaktadır. Aynı şekilde çalışma alanının kuzeybatı ve güneydoğu kısımlarının düşük ve orta uygunlukta çıkması bu kesimlerde eğitim, hastane ve kamu kurumlarının olmaması ya da çok az olmasindandir.

\subsubsection{YGA1: Uygun konut alanlarının belirlenmesi}

Kullanılan veriler: Doğal çevre (YGA1A11) ve beşeri çevre (YGA1A12) özellikleri bakımından uygun konut alanlarına ait amaçların analiz verileridir.

Değer atama kriteri: Konut yerleşimi için belirlenen iki amaç raster hesaplama aracı ile doğal unsurlara \%50, beşeri unsurlara \%50 oranında ağırlık verilerek birleştirilmiştir.

Değer atama gerekçesi: Konut yerleşimi için uygun alanların belirlenmesinde birleştirme yapılırken doğal ve beşeri unsurların aynı oranda etkili olacağı düşünülmüş ve yapılan literatür taramasında da daha önce yapılan çalışmaların (Nayim, 2011; Taşdemir, 2017) birleştirmeyi aynı oranda yaptıkları görülmüş ve buna göre birleştirme değerleri belirlenmiştir. Bu değerlendirme ticaret ve sanayi yerleşimi analizleri için de geçerlidir.

Analizin yorumlanması: Harita 4'te görüldüğü üzere çalışma alanında mevcut konutların yoğunlukta olduğu güney kısımlar burada da yüksek uygunlukta çıkmıştır. Ancak her ne kadar güneyde kıyı kesimler konut yerleşimi açısından yüksek uygunlukta çıksa da çalışma alanının Marmara Bölgesinde yer aldığı ve deprem riski açısından kıyı alanlarının yerleşim üzerinde bir tehdit unsuru olduğu unutulmamalıdır.

Çalışma alanından kuzeye gittikçe konutların azalması, ulaşım ağlarının sıklığının düşmesi, okul, hastane gibi kamu

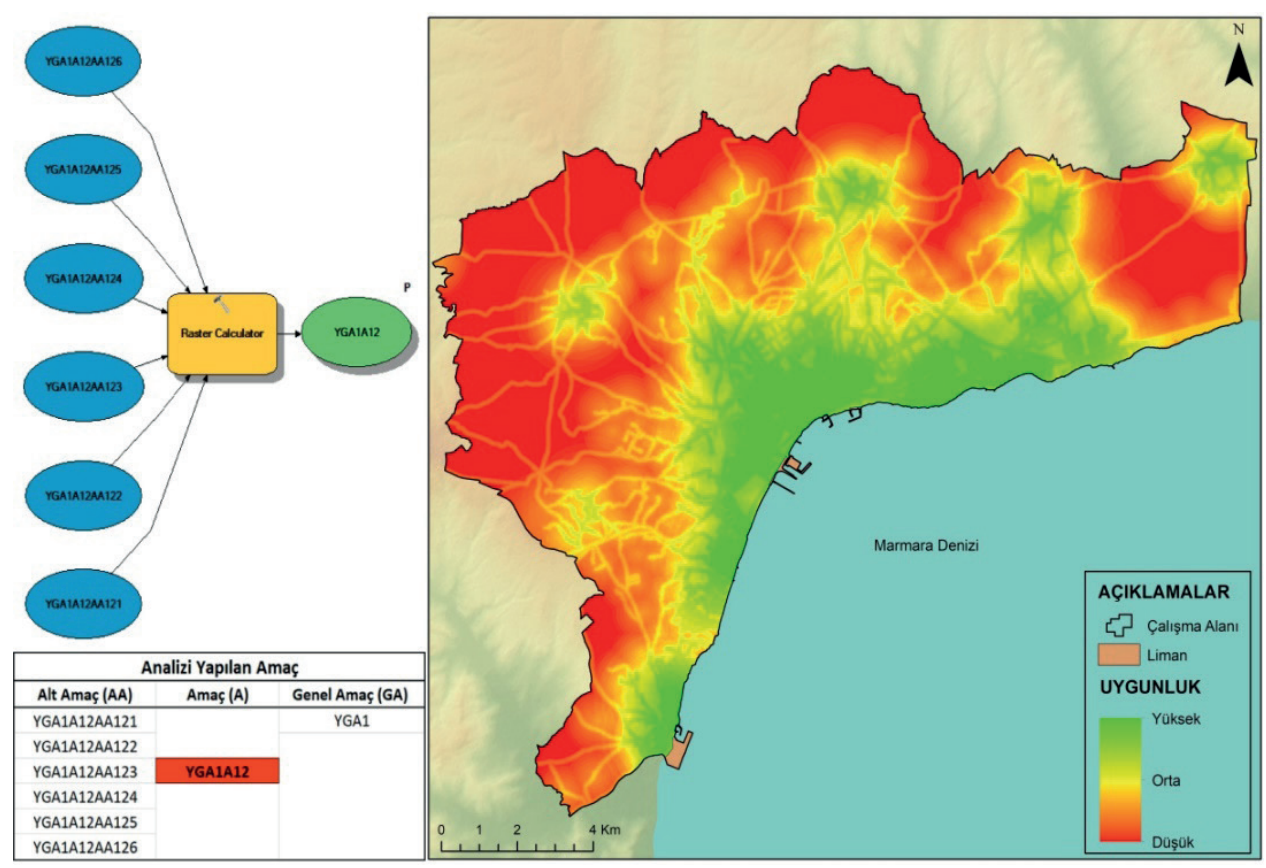

Harita 3: YGA1A12- Beşeri Bakımdan Konut Yerleşimine Uygun Alanların Analizi. Map 3: Human Conformity Analysis for Residential Settlements. 


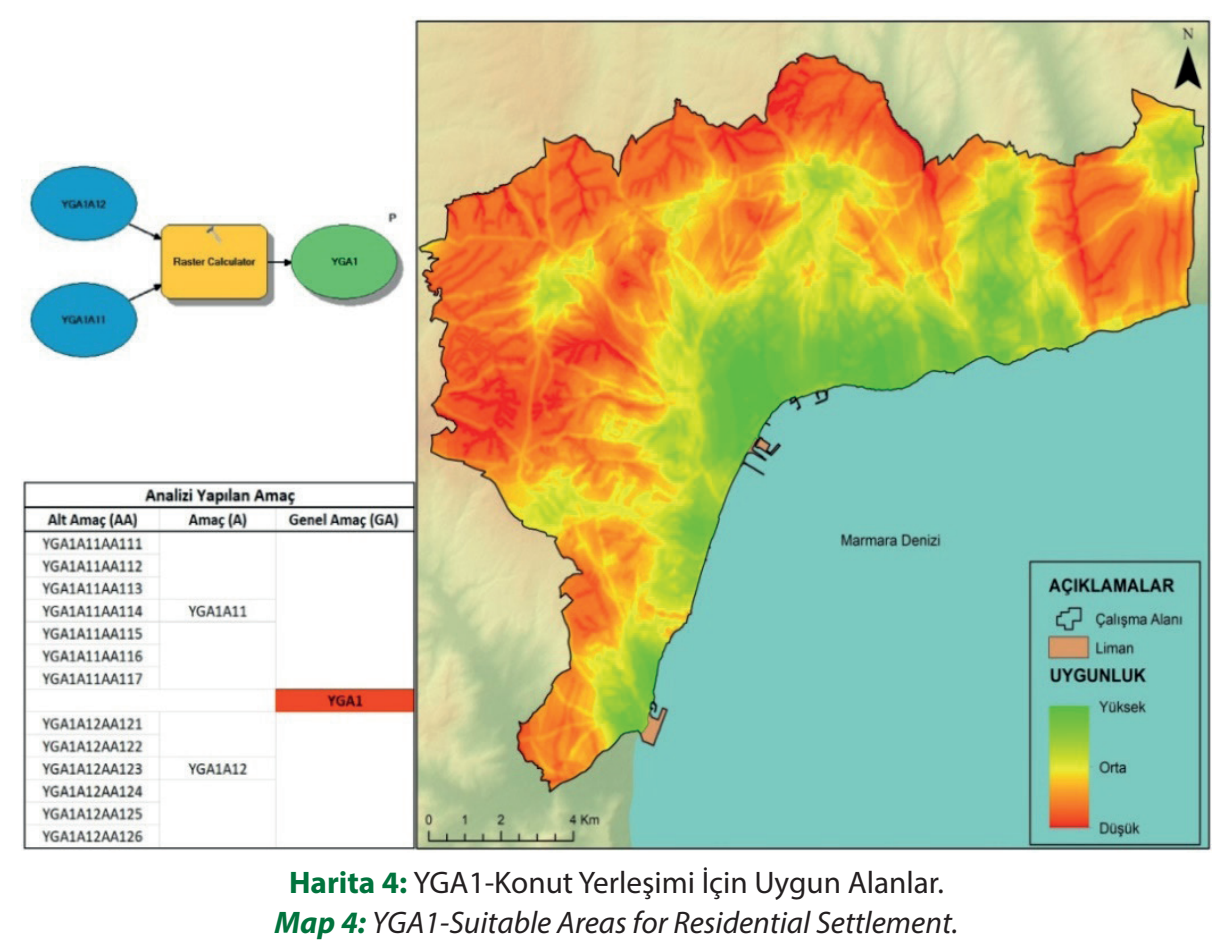

kurumlarının sayısının azalması yerleşim için buraların orta veya yer yer düşük uygunlukta çıkmasına neden olmuştur. Özellikle dere yataklarının olduğu kuzeybatı, kuzey ve kuzeydoğu kısımları konut yerleşimi açısından düşük uygunlukta sahalar niteliğindedir.

Konut yerleşimi için uygunluk analizinin çalışma alanındaki dağılımına bakıldığında \%41,20 (7363,56 ha.) ile en büyük oran orta uygunluk alanlarında görülmektedir. Özellikle çalışma alanının orta kısımlarında ve yüksek uygunluk görülen alanların yakın çevrelerinde görülen bu sahalar çalışma alanının geneline dağılmış durumdadır. Bunu \%34,54 (6173,58 ha.) ile düşük uygunluk görülen alanlar takip etmektedir. Özellikle dere yatakları ve bunların yakın çevresi düşük uygunluğun görüldüğü yerler durumundadir.

Çalışma alanında \%24,26 (4336,96 ha.) konut yerleşimi açısından yüksek uygunlukta çıkmıştır. Tüm doğal ve beşeri unsurlara göre en uygun konut yerleşimlerinin görüldüğü bu alanlar, çalışma sahasının güneyinde merkez ve sahil boyunca yoğunlaşmaktadır. Kuzeye gittikçe yüksek uygunluğun orta uygunluğa dönüştüğü çalışma alanının kuzeyinde uygunluklar belli noktalarda toplanmış durumdadır. Eski köy yerleşmeleri olan ancak günümüzde Tekirdağ şehrinin birer mahallesi haline gelen bu yerleşmelerden çalışma alanının kuzeydoğusunda yer alan Gazioğlu ve onun hemen batısındaki Köseilyas ve Kayı mahallelerinde yüksek uygunluk çıkan alanlar daha geniş yer tutmuştur. Bunun en önemli nedeni bu yerleşim birimlerinin kuzeydeki diğer mahallelere göre hane sayısı, ulaşım ağları ve diğer kamu kurumları açısından daha fazla gelişmiş olmalarıdır. Çalışma alanının güneydoğusunda yer alan ve Namık Kemal Üniversitesini de içine alan Köseilyas mahallesinin Tekirdağ şehri ile kesintisiz bir konut yerleşim uygunluğu gösterdiği, hatta bunun hemen batısında yer alan Kayı mahallesine de bu durumun yansıdığı görülmektedir (Harita 4).

\subsection{YGA2: Ticaret için uygun alanların belirlenmesi}

Yerleşim kategorisi içerisindeki genel amaçlardan biri olan ticaret yerleşimi için uygun olan alanların (YGA2) belirlenmesinde doğal ve beşeri olmak üzere 2 amaç ve 14 alt amaç bulunmaktadır.

\subsubsection{YGA2A21: Doğal çevre özellikleri bakımından uygun ticaret alanlarının belirlenmesi}

Uygunluk analizleri yapılırken yerleşim kategorisi içinde yer alan konut ve ticaret alanlarında doğal çevre özellikleri bakımdan uygun alanlarının belirlenmesi amacı, her iki genel amaç içinde aynı şeyleri temsil etmektedir. $\mathrm{Bu}$ yüzden ilgili şekil ve alan dağılımları burada tekrara düşmemek için yeniden verilmemiş ancak modelin bütünlüğü açısından ilgili alt amaçlar ticaret alanları içinde analiz edilmiştir. 
3.2.2. YGA2A22: Beşeri çevre özellikleri bakımından uygun ticaret alanlarının belirlenmesi

Beşeri çevre özellikleri açısından ticaret yerleşimine uygun alanların belirlendiği YGA2A22 amaç analizinde 7 alt amaç kullanılmıştır (Tablo 4).

Tablo 4: YGA2A22 Amacında Kullanılan Veriler ve Değer Atama Kriterleri. Table 4: Data and Value Assignment Criteria Used for YGA2A22 Purpose.

\begin{tabular}{lllc}
\hline \multirow{2}{*}{ Sıra } & \multicolumn{1}{c}{ Kullanılan Veriler } & Değer Atama Kriteri \\
\cline { 2 - 4 } & \multicolumn{1}{c}{ Kod } & \multicolumn{1}{c}{ Alt Amaç } & Oran (\%) \\
\hline 1 & YGA2A22AA221 & Mevcut konutlar & 20 \\
2 & YGA2A22AA222 & Mevcut ticaret alanları & 30 \\
3 & YGA2A22AA223 & Hastane ve sağlık kurumları & 10 \\
4 & YGA2A22AA224 & Eğitim kurumları & 10 \\
5 & YGA2A22AA225 & İdari kurumlar (kaymakamlık, & 10 \\
& & belediye binası vd.) & 10 \\
6 & YGA2A22AA226 & Parklar, tarihi mekanlar ve & \\
& & diğer rekreasyon alanları & 10 \\
7 & YGA2A22AA227 & Ulaşım ağları &
\end{tabular}

Değer atama gerekçesi: Ticaret yerleşimine beşeri çevre özellikleri bakımdan uygunluk analizi yapılırken en yüksek değer alt amaçlardan mevcut ticaret alanlarına yakın alanların belirlenmesi (YGA2A22AA222) analizine verilmiştir. Çünkü mevcut ticarethanelerin yeni yapılacak ticarethaneleri kendine çekeceği varsayılmıştır. Daha sonra en yüksek değer \%20 ile mevcut konutlara yakın alanların analiz edildiği
YGA2A22AA221'e verilmiştir. Çünkü ticaret alanlarının konutların yakınında olması insanların ihtiyaçlarının daha kolay giderilmesini sağlayacaktır. Geriye kalan sağlık, eğitim, kamu kurumları, parklar, tarihi mekânlar ve ulaşım ağlarını alt amaçlarına ise \%10 ağırlık verilmiştir. Bunun nedeni bu kriterlerin ticaret yerleşimi üzerinde aynı oranda etkili olacağının düşünülmesidir.

Analizin yorumlanması: Ticaret yerleşimi açısından çalışma alanının 10965,97 (\%61,35) hektarı düşük uygunlukta çıkmıştır. Özellikle çalışma alanının kuzeyinde yoğunlaşan bu alanlar ulaşım ağlarının seyrekleştiği, konut, sağlık, eğitim ve kamu kurumlarının azaldığı, mevcut ticarethanelerin olmadığ yerlerde görülmektedir (Harita 5).

Çalışma alanının \%22,03’ü (3937,94 ha.) orta uygunluk görülen yerlerden oluşmaktadır. Güneyde yoğunlaşan yüksek uygunluk alanları kuzeye gittikçe seyrekleşmekte ve orta uygunluğa dönüşmektedir. Kuzeyde ise Tekirdağ şehir merkezine daha uzak olan Gazioğlu, Kayı ve Köseilyas gibi mahallelerde yer alan bakkal, kahvehane gibi küçük işletmeler bu yerleşmelerin ticaret yerleşimi açısından diğer uzak mahallelere göre görece daha yüksek uygunlukta çıkmasına (\%16,62 - 2970,20 ha.) neden olmuştur. Özellikle ulaşım ağları ile de uyum içerisinde olan bu alanlar ticaret yerleşimi için yüksek uygunluk görülen yerler arasındadir.

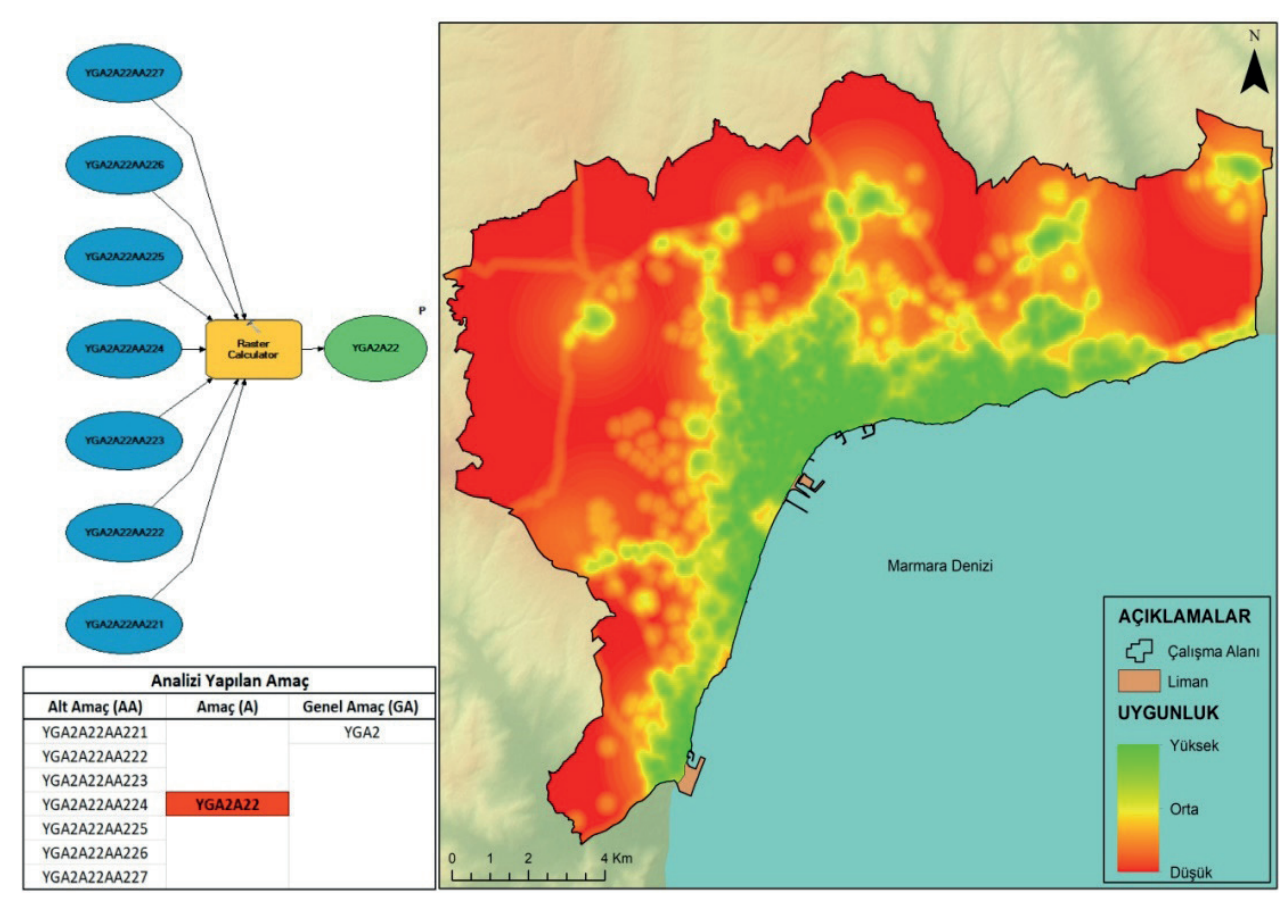

Harita 5: YGA2A22-Ticaret Yerleşimine Beşeri Bakımdan Uygun Alanların Analizi.

Map 5: YGA2A22- YGA2A22-Analysis of Areas Suitable for Commercel in Terms of Human Conditions. 


\subsubsection{YGA2: Uygun ticaret alanlarının belirlenmesi}

Kullanılan veriler: Doğal çevre (YGA2A21) ve beşeri çevre (YGA2A22) özellikleri bakımından uygun ticaret alanlarına ait amaçların analiz verileridir.

Değer atama kriteri: Ticaret alanları için belirlenen iki amaç raster hesaplama arac1 ile doğal unsurlara \%50, beşeri unsurlara \%50 oranında ağılık verilerek birleştirilmiştir.

Değer atama gerekçesi: Ticaret alanları için uygunluk analizinde doğal ve beşeri unsurların aynı oranda etkili olacağı düşünülmüştür.

Analizin yorumlanması: Çalışma alanının yarısı ( $\% 50,19$ - 8970,84 ha.) ticaret alanları için düşük uygunlukta çıkmıştır. Aynı konut yerleşiminde olduğu gibi ticaret alanlarında da düşük uygunluk görülen alanlar daha çok çalışma alanının kuzey kısımlarında dere, dere kolları ve tarım alanları ile yerleşim unsurları bulunmayan yerlerde yoğunlaşmaktadır (Harita 6).

Ticaret yerleşimine orta uygunlukta çıkan yerler 5627,13 hektar alan kaplamakta $(\% 31,48)$ ve bu alanlar daha çok yüksek uygunluk görülen yerlerin çevresinde ve ulaşım ağlarına yakın alanlarda görülmektedir. Yüksek uygunluk görülen alanlar ise 3276,13 hektar ile toplam alanın \%18,33'üne tekabül etmektedir. Özellikle çalışma alanının güneyinde yoğunlaşan bu alanlar merkezden uzaklaştıkça azalmakta, kuzeyde ise düşük uygunluk alanlarına dönüşmektedir.

\subsection{YGA3: Sanayi için uygun alanların belirlenmesi}

Yerleşim kategorisi içerisindeki genel amaçlardan biri olan YGA3 doğal ve beşeri olmak üzere 2 amaç ve 10 alt amaçtan oluşmaktadır.

\subsubsection{YGA3A31: Doğal çevre özellikleri bakımından uygun sanayi alanlarının belirlenmesi}

Doğal çevre özellikleri açısından sanayi yerleşimine uygun alanların belirlendiği YGA3A31 amaç analizinde 5 alt amaç kullanılmıştır (Tablo 5).

Tablo 5: YGA3A31 Amacında Kullanılan Veriler ve Değer Atama Kriterleri. Table 5: Data and Value Assignment Criteria Used for YGA3A31 Purpose.

\begin{tabular}{cclc}
\hline \multirow{2}{*}{ Sıra } & \multicolumn{2}{c}{ Kullanılan Veriler } & Değer Atama Kriteri \\
\cline { 2 - 4 } & \multicolumn{1}{c}{ Kod } & \multicolumn{1}{c}{ Alt Amaç } & Oran (\%) \\
\hline 1 & YGA3A31AA311 & Sel riski & 40 \\
2 & YGA3A31AA312 & Eğim & 10 \\
3 & YGA3A31AA313 & Zemin özellikleri & 10 \\
4 & YGA3A31AA314 & Deprem ve heyelan riski & 15 \\
5 & YGA3A31AA315 & Su kaynakları (dere, göl ve & 25 \\
& & gölet) \\
\hline
\end{tabular}

Değer atama gerekçesi: Sanayi yerleşimine doğal çevre özellikleri bakımdan uygun alanlar tespit edilirken burada en yüksek ağırlık sel riski olan YGA3A31AA311 analizine

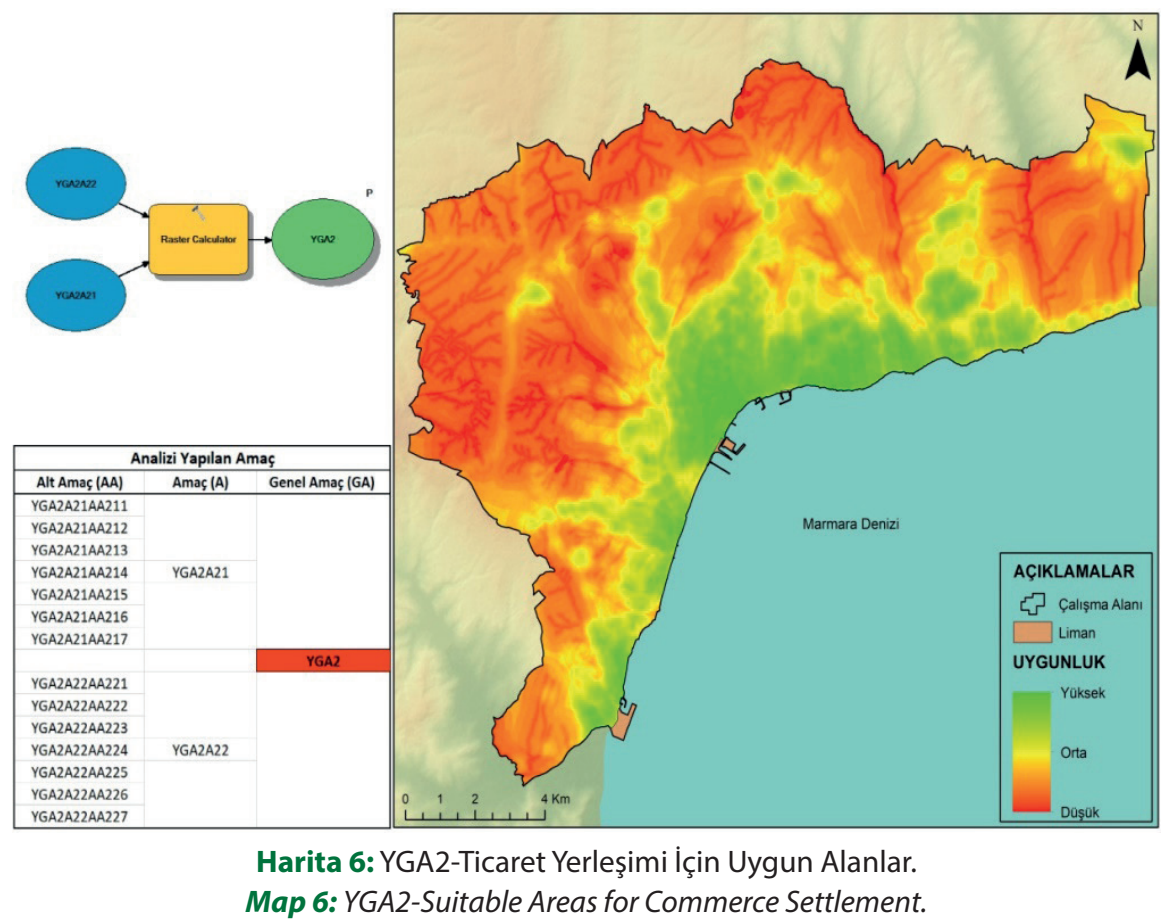


verilmiştir. Çünkü bir yerde sel ve taşkın olması sanayi yerleşimlerini büyük oranda etkileyecek ve mali zararlara neden olacaktır. Aynı şekilde su kaynaklarından uzak alanların daha uygun olacağı düşünülmesi su kütlelerini kirletmemesi açısından oldukça önemli görülmüş ve birleştirilirken YGA3A31AA315 analizine $\% 25$ oran verilmiştir. Heyelan, eğim ve jeoloji alanlarına göre uygunluklarda oranlar hemen hemen birbirine yakın tutulmuş ve aynı oranda etkili olabileceği düşünülmüştür.

Analizin yorumlanması: Çalışma alanının yarısından fazlası (\%53,82-9622,03 ha.) doğal çevre özellikleri açısından sanayi yerleşimine yüksek uygunlukta çıkmıştır. Harita 7'ye bakıldığında yüksek uygunluk görülen alanlar dere yatakları ve bunların çevreleri hariç çalışma alanının geneline yayılmış durumda olduğu görülmektedir.

2678,20 hektar alan kaplayan düşük uygunluk alanları $(\% 14,98)$ daha çok dere ve dere kollarının geçtiği yerlerde görülmektedir. Hem sel riski açısından hem de su yüzeylerinin kirlenmemesi açısından dere yatakları sanayi yerleşimi açısından en düşük uygunlukta görülen yerler olmuştur. Orta uygunluk görülen alanlar daha çok dere yataklarının çevresinde yoğunlaşırken toplam alanın \%31,18'ine tekabül etmekte (5573,89 ha.) ve derelerin çevresinde yüksek uygunluk alanları ile kesişim noktalarında yoğunlaşmaktadır (Harita 7).
3.3.2. YGA3A32: Beşeri çevre özellikleri bakımdan uygun sanayi alanların belirlenmesi

Beşeri çevre özellikleri açısından sanayi yerleşimine uygun alanların belirlendiği YGA3A32 amaç analizinde 5 alt amaç kullanılmıştır (Tablo 6).

Tablo 6: YGA3A32 Amacında Kullanılan Veriler ve Değer Atama Kriterleri. Table 6: Data and Value Assignment Criteria Used for YGA3A32 Purpose.

\begin{tabular}{cclc}
\hline \multirow{2}{*}{ Sıra } & \multicolumn{2}{c}{ Kullanılan Veriler } & Değer Atama Kriteri \\
\cline { 2 - 4 } & \multicolumn{1}{c}{ Kod } & \multicolumn{1}{c}{ Alt Amaç } & Oran (\%) \\
\hline 1 & YGA3A32AA321 & Mevcut konutlar & 50 \\
2 & YGA3A32AA322 & Mevcut sanayi alanları & 20 \\
3 & YGA3A32AA323 & Ana ulaşım yolları & 10 \\
4 & YGA3A32AA324 & Demiryolları & 10 \\
5 & YGA3A32AA325 & Limanlar & 10 \\
\hline
\end{tabular}

Değer atama gerekçesi: Sanayi yerleşiminin beşeri çevre özellikleri bakımdan uygunluğu analiz edilirken en yüksek ağırlık (\%50) konuttan uzak alanların analiz edildiği YGA3A32AA321'e verilmiştir. Çünkü sanayi faaliyetlerinden bazılarının üretim esnasında çok fazla ses çıkarması, hava kalitesini etkilemesi ve taşımacılık esnasında çok fazla yük araçlarının kullanması konut yerleşimlerini olumsuz etkileyecektir.

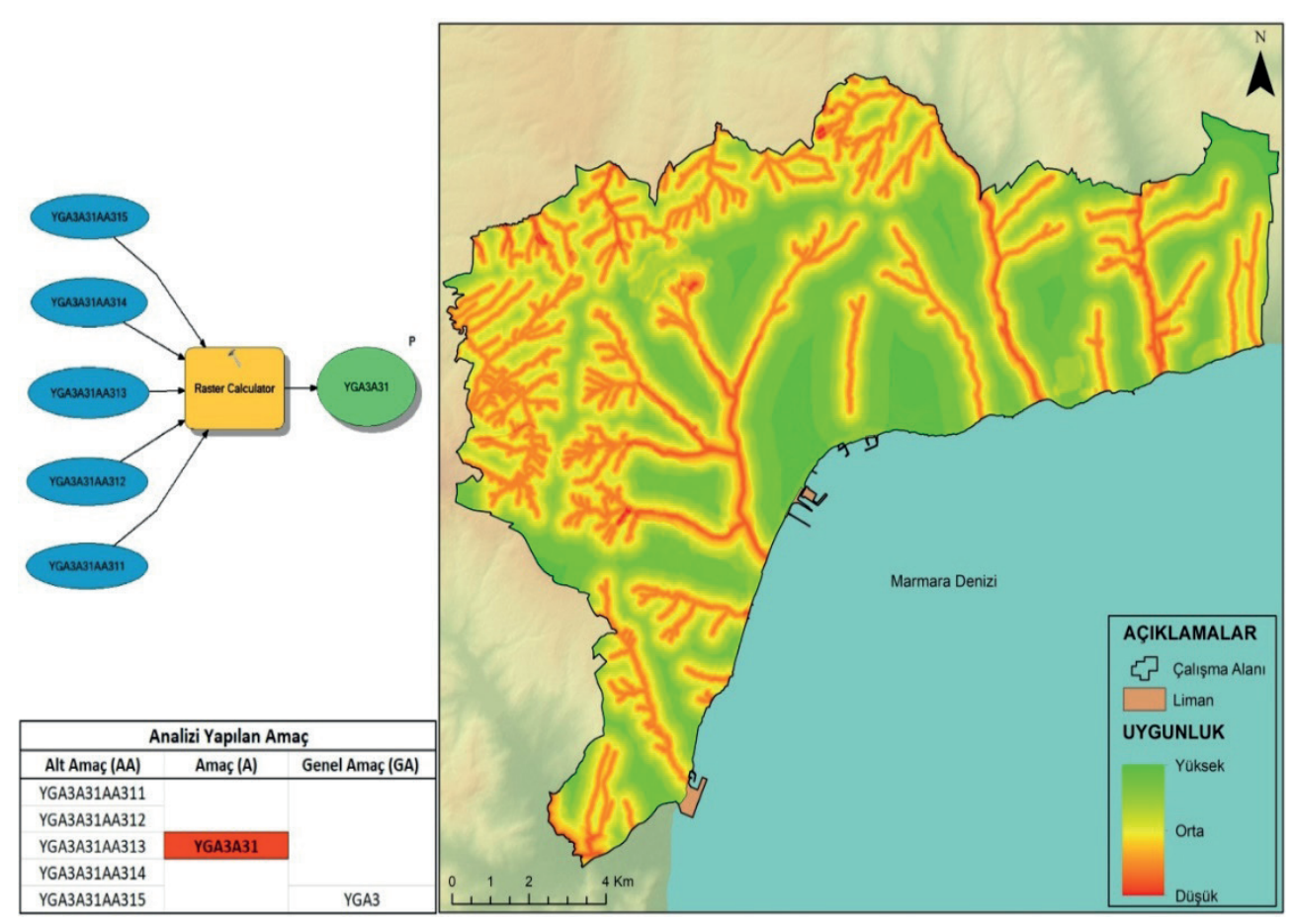

Harita 7: YGA3A31-Doğal Çevre Özellikleri Bakımından Sanayi Yerleşimine Uygun Alanlar. Map 7: YGA3A31-Areas Suitable for Industrial Settlement in terms of Physical Conditions. 
Yeni sanayi yerleşimlerinin mevcut sanayi alanlarına yakın kurulmasının daha uygun olacağı düşünüldüğü için bu analize de $\% 20$ ağırlık verilmiştir. Bu durum sanayi alanlarının daha fazla alana yayılmasını önleyeceği gibi ve sanayi alanlarının belli yerlerde toplanmasını da sağlayacaktır. Ulaşım sistemlerine ise aynı oranda değerler verilerek sanayi yerleşimi üzerinde aynı oranda etkili olacağı düşünülmüştür.

Analizin yorumlanması: Çalışma alanının 6985,26 hektarı $(\% 39,08)$ sanayi yerleşimine beşeri çevre özellikleri bakımdan düşük uygunlukta çıkmıştır. Bunu 6232,58 hektarla $(\% 34,87)$ orta uygunluk görülen alanlar takip etmektedir. Özellikle konut alanlarının yoğun olduğu yerlerde düşük uygunluk görülen çalışma alanının doğusunda, mevcut sanayi alanları daha az olduğu için buralarda düşük uygunluk görülen alanlar daha belirgin bir hal almıştır (Harita 8).

Mevcut sanayi alanlarının daha çok çalışma alanının orta kısımlarında toplanması, konut alanlarının ve ulaşım ağlarının da bu bölgede yoğunlaşmasından dolayı buraların sanayi yerleşimi için orta uygunlukta çıkmasına, konut yerleşimlerinden uzaklaştıkça yüksek uygunluk alanlarının (\%26,05-4656,27 ha.) artmasına neden olmaktadır (Harita 8).

\subsubsection{YGA3: Uygun sanayi alanlarının belirlenmesi}

Kullanılan veriler: Doğal çevre (YGA3A31) ve beşeri çevre (YGA3A32) özellikleri bakımından uygun sanayi alanlarına ait amaçların analiz verileridir.

Değer atama kriteri: Sanayi alanları için belirlenen iki amaç raster hesaplama aracı ile doğal unsurlara $\% 50$, beşeri unsurlara $\% 50$ oranında ağırlık verilerek birleștirilmiştir.

Değer atama gerekçesi: Sanayi yerleşimi için uygun alanların belirlenmesinde doğal ve beşeri unsurların aynı oranda etkili olacağı düşünülmüştür.

Analizin yorumlanması: Çalışma alanının 8465,00 hektarı $(\% 47,36)$ sanayi yerleşimi açısından orta uygunlukta çıkmıştır. Çalışma alanının geneline yayılan bu alanlar daha çok derelerin çevresinde yüksek uygunluk alanları ile kesişim bölgelerinde görülmektedir. Özellikle dere yataklarında sel-taşkın olma ihtimalinin olması ve suların kirlenmesine karşı korunması istendiği için düşük uygunluk görülen yerler (\%22,33-3990,78 ha.) dere yataklarında görülmüştür (Harita 9).

Çalışma alanının 5418,33 hektarı (\%30,31) sanayi yerleşimi için yüksek uygunluk değerine sahiptir. $\mathrm{Bu}$ alanlar daha çok çalışma alanının orta kısmında yer alıyor olsa da genel olarak çalışma alanının tamamında küȩük parçalar halinde yer almaktadır.

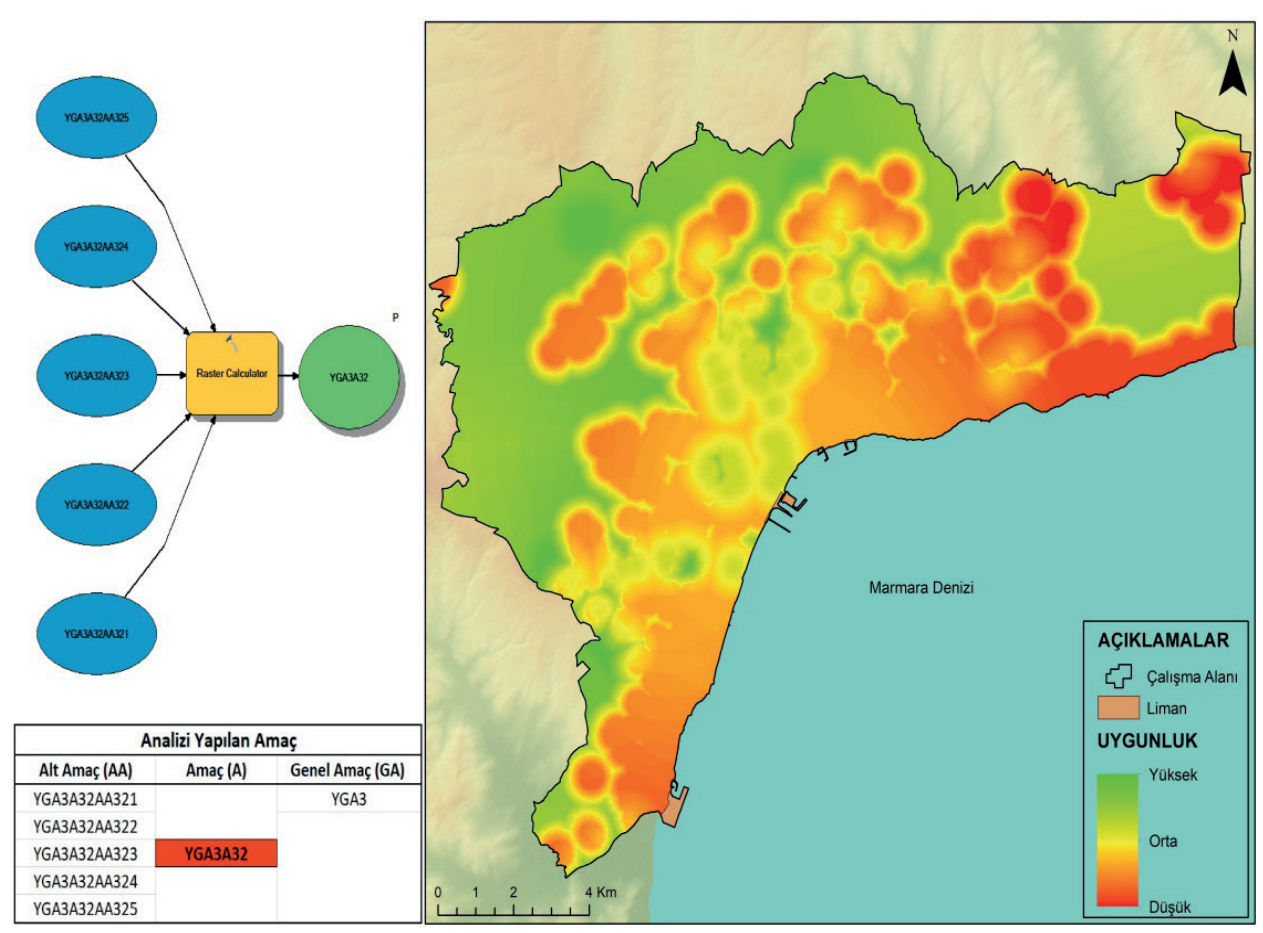

Harita 8: YGA3A32- Beşeri Çevre Özellikleri Bakımından Sanayi Yerleşimine Uygun Alanlar. Map 8: Analysis of Areas Suitable for Industry in Terms of Human Conditions. 


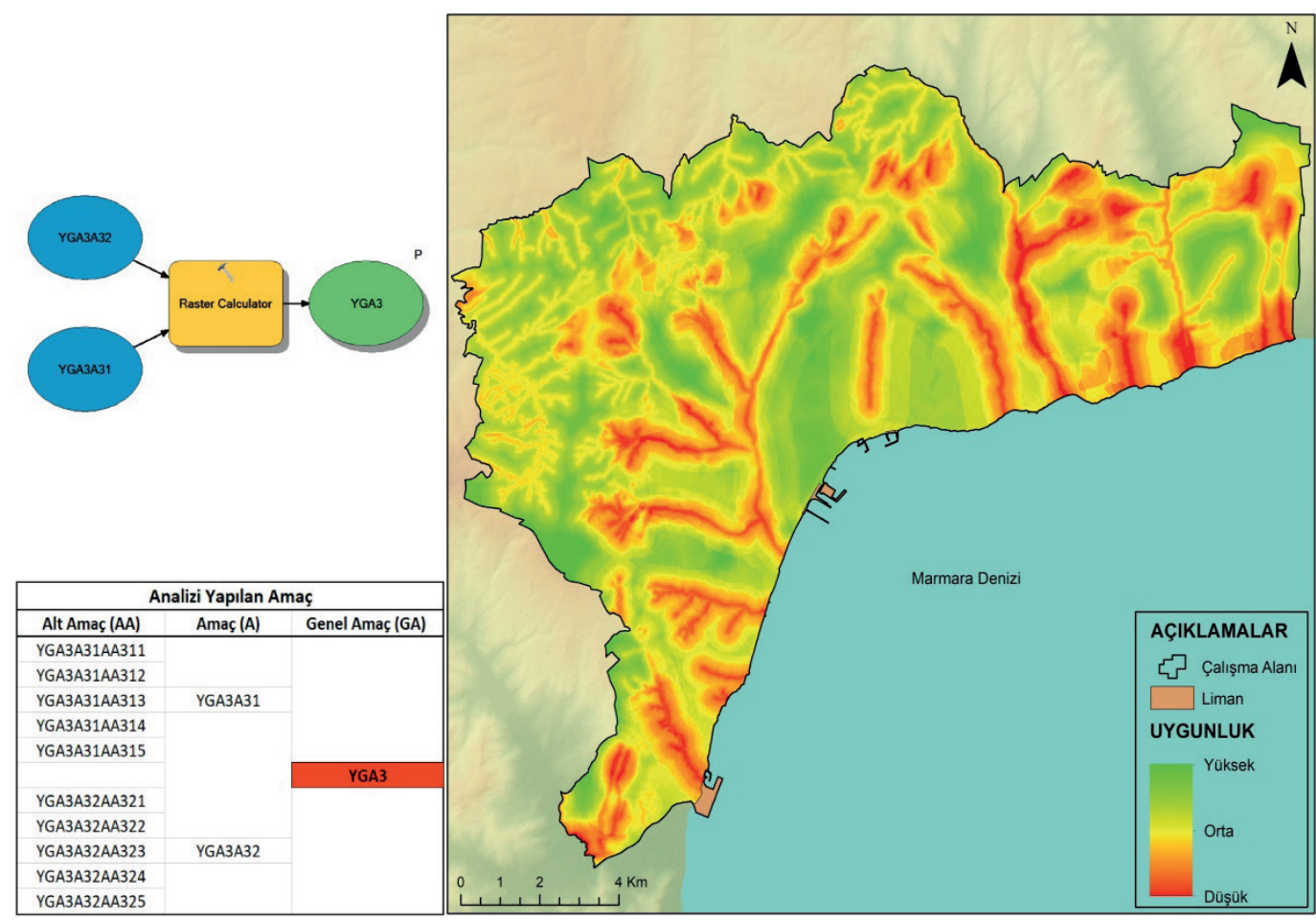

Harita 9: YGA3-Sanayi Yerleşimi İçin Uygun Alanlar.

Map 9: YGA3-Suitable Areas for Industrial Settlement.

\subsection{Yerleşim kategorisi için nihai uygunluğun belirlenmesi} (YKA)

Kullanılan veriler: Konut (YGA1), ticaret (YGA2) ve sanayi (YGA3) yerleşimi için uygun alanların belirlenmesi genel amaçlarına ait analiz verileridir.

Değer atama kriteri: YKA ait analiz yapılırken raster hesaplama aracı kullanılmış ve YGA1'e ait genel amaca \%60, YGA2'ye ait genel amaca \%20 ve YGA3'e ait genel amaca \%20 ağırlık verilerek birleştirilmiştir.

Değer atama gerekçesi: Yerleşim alanlarına ait tercihlerin ve nihai uygunlukların belirlenmesinde en yüksek yüzde konut alanlarına verilmiştir. Bunun temel nedeni mevcut yerleşim alanlarının \%58,93'ünü konut alanları, \%21,52'sini ticaret alanları ve \% 19,55'ini sanayi alanları kapladığı için birleştirme yapılırken de bu mevcut dağılışları dikkate alınmış ve yuvarlanarak oranlar belirlenmiştir.

Analizin yorumlanması: Yerleşime ait üç genel amacın tek bir kategoride birleştiği ve ağırlık tercihlerine göre yerleşim kategorisi için belirlenen nihaî alan kullanım uygunluklarının belirlendiği Harita 10'a bakıldığında, güneye gittikçe yerleşim baskısı artmakta ve uygunluk buralarda yüksek çıkmaktadır.

Konut, ticaret ve sanayi yerleşimi açısından uygunluk analiz sonuçlarına göre, çalışma alanının 3539,87 hektarı yüksek uygunluktadır. Toplam alanın \%19,80'ini kaplayan yüksek uygunluk alanları daha çok çalışma alanının güney, güneybatı ve güneydoğu kısımlarında, kuzeydeki eski köy yerleşmeleri olan ama günümüzde Tekirdağ şehrinin birer mahallesi haline gelen en kuzeydoğudaki Gazioğlu ve sırasıyla batıya doğru Köseilyas, Kayı ve Yağcı mahallelerinde yoğunlaşmaktadır.

Konut, ticaret ve sanayi genel amaçlarına ait birleştirme sonucunda elde edilen yerleşim kategori amacında (YKA) 6665,84 hektar alan kaplayan orta uygunluk alanları toplam alanın \%37,29'unu oluşturmaktadır. Özellikle güneydeki yüksek uygunluk çevresinde yoğunlaşan orta uygunluk alanları çalışma alanının geneline hâkim olmuş ve tüm yüksek ve düşük uygunluk görülen yerleri çevrelemiştir (Harita 10).

Çalışma alanı içerisinde YKA açısından düşük uygunluk görülen alanlar 7668,40 hektar alan kaplamakta ve toplam alanının \%42,90'ını kapsamaktadır. Yerleşim açısından düşük uygunlukta olan bu alanlar daha çok dere, dere yatakları ve 
bunların yakın çevrelerinde yer alırken, çalışma alanının kuzey kısmının neredeyse tamamında görülmekte ve bu alanlar yerleşim alanları açısında düşük uygunluk değerine sahip olmaktadır.

Genel olarak derelerin ve dere kollarının yerleşim açısından -hangi yerleşim türü olursa olsun- hiçbir zaman yerleşime açılmaması gereken yerler olduğu tüm kamu kurum ve kuruluşları, özel ve tüzel kişiler tarafindan bilinmeli ve buralar yerleşime asla açılmaması gereken yerler olarak görülmelidir. Bunlar sadece kanun ya da temenniler ile kalmamalı pratikte de böyle olmalıdır. Nihayetinde LUCIS modelinin uygulandığı ve birçok alt amacın sorgulandığg ve sonuç olarak YKA elde edildiği Harita 10'un analiz sonucuna bakıldığında bu tespitin doğru olduğu ve dere yataklarının yerleşim açısından düşük uygunluk değerine sahip olduğu ve yerleşime uygun olmadığı görülmektedir.

\section{TARTIŞMA VE SONUÇ}

Şehirlerin kurulmasından gelişmesine kadar tüm süreçlerin coğrafi perspektifte değerlendirilmesi ve coğrafi unsurların göz ardı edilmeden büyümesinin desteklenmesi şehirlerin tüm diş unsurlara karşı daha güvenli olmasını destekleyecektir. Tüm bu ortamın oluşturulabilmesi için yerleşimlerde şehir planlamaları yapılmalı, ileriye dönük tahminler ve modeller geliştirilmeli, şehrin gelişim aksları ve uygunlukları belirlenerek genişleyeceği çevre üzerindeki olumsuz baskısı en aza indirilmelidir.

Çalışmamızda uygulama yöntemi olarak tercih edilen LUCIS modeli, kullanıcılarına konut, ticaret ve sanayi gibi yerleşim alanlarının uygunluk analizini yapmakta hatta bir sonraki aşamasında gelecekteki alan kullanım uyuşmazlıklarını analiz etme firsatı sunmaktadır.

Tekirdağ şehrinin konut, ticaret ve sanayi yerleşimi açısından uygunluk analizinin yapıldığ 1 bu çalışmada, doğal ve beşeri coğrafya faktörlerinin yerleşim üzerindeki etkileri tek tek analiz edilerek tüm yerleşim türleri için en uygun yerlerin tespit edilmesi amaçlanmıştır. Tüm bu analizler şehrin konut, ticaret ve sanayi yerleşimine hem doğal ve hem de beşeri unsurlar açısından en uygun yerleri tespit edebilme firsatı sunarken; her iki unsurun birleştirilmesi ile konut, ticaret ve sanayi yerleşimi için en uygun yerlerin tek bir harita üzerinde analizine de imkân sunmaktadır.

Çalışmada öncelikle tüm yerleşim unsurlarının doğal ve beşeri bakımdan uygunluklarının analizi gerçekleştirilmiş, daha sonra konut, ticaret ve sanayi alanları için en uygun yerlerin tespiti yapılmıştır. Son aşamada yerleşim kategorisi için nihai uygunluklar belirlenmiştir.

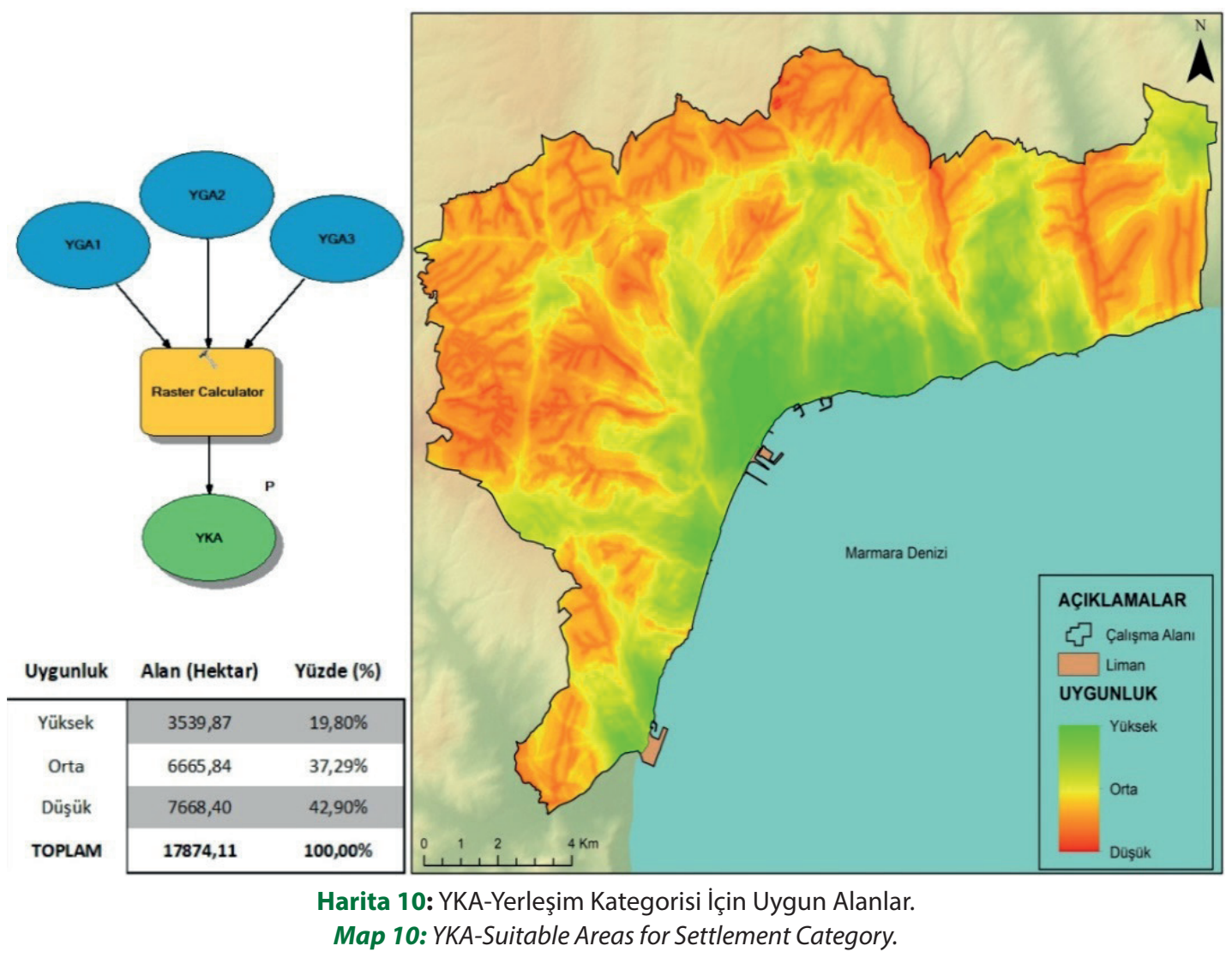


Doğal ve beşeri unsurların birlikte değerlendirildiği konut yerleşimi için uygunluk analizinde (YGA1) çalışma alanının \%24,26'sı konut yerleşimine yüksek uygunlukta çıkmıştır. Özellikle çalışma alanının güney bölümlerinde Tekirdağ şehir merkezinde yoğunlaşan yüksek uygunluk alanları kuzeye gittikçe düşük uygunluk alanlarına dönüşmektedir. Dere yatakları, heyelan bölgeleri ve mevcut konutlardan uzak alanlar, konut yerleşimi açısından düşük yoğunluğun en fazla görüldüğü yerler olmuştur.

Ticaret için uygunluk analizinin yapıldığ1 YGA2 analizi sonuçlarına göre, çalışma alanının yarısından fazlası $(\% 50,19)$ düşük uygunluk görülen alanlardan oluşmaktadır. Konut alanlarına göre çalışma alanında daha az yer kaplayan ticaret alanları için yüksek uygunluk görülen sahalar, ulaşım ağlarına, mevcut konut ve ticaret yerleşimine yakın yerlerde yoğunlaşmaktadır. Konut alanlarında olduğu gibi burada da dere ve dere kolları ticaret yerleşimi için en düşük uygunluğun görüldüğü yerler olmuştur.

Sanayi yerleşimi uygunluk analizinde (YGA3) çalışma alanının \%47,36'sı orta uygunlukta çıkmıştır. Oluşabilecek sel ve taşkınlara karşı dere yataklarından uzak kurulması istenen sanayi alanları dere yataklarının olduğu yerlerde yoğun şekilde düşük uygunlukta çıkmıştır.

Konut, ticaret ve sanayi alanlarının birlikte değerlendirildiği YKA çalışma alanının yerleşim açısından uygunluğu analiz edilmiştir. Tekirdağ şehrinin \%19,80 (3539,87 ha.) yüksek uygunlukta çıkmıştır. Mevcut şehir merkezini de içine alan yüksek uygunluk alanları şehrin kurulmasında doğal ve beşeri unsurların göz ardı edilmediğinin en büyük kanıtıdır. Şehir merkezinden uzaklaştıkça uygunluklar belli yerlerde yoğunlaşırken eski köy yerleşmeleri olan ancak günümüzde Tekirdağ şehrinin birer mahallesi haline gelen Köseilyas ve Kayı mahallelerinde de uygunluk kesintisiz devam etmektedir. $\mathrm{Bu}$ durum açıkça göstermektedir ki şehrin gelişim yönü ilerleyen süreçte kuzey, kuzeybatı ve kuzeydoğu yönünde gerçekleşecektir (Harita 11). Çünkü bu bölgeler konut, ticaret ve sanayi yerleşimi için en uygun yerleri içinde barındırmaktadır.

Dere yatakları yerleşim açısından her zaman tehlikeli alanları temsil etmektedir. Çalışma alanı içerisinde 7668,40 hektar $(\% 42,90)$ alan kaplayan düşük uygunluk alanları daha çok dere

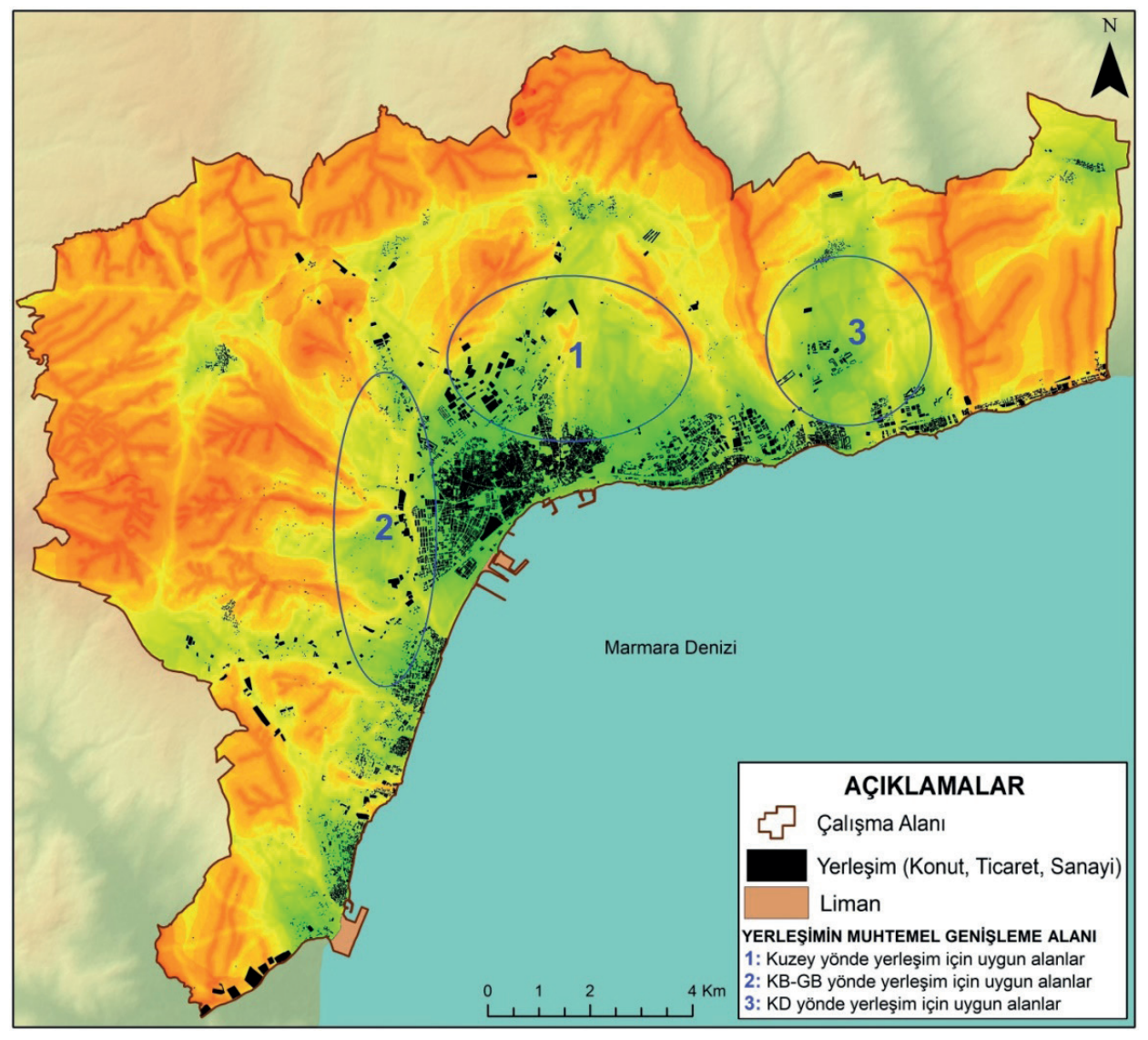

Harita 11: Tekirdağ Şehrinde Yerleşimin Muhtemel Genişleme Yönleri. Map 11: Likely Extention Directions of Settlement in Tekirdağ City. 
yatakları ve bunların yakın çevrelerinden oluşmaktadır. $\mathrm{Bu}$ alanlar yerleşmeye açılmayarak şehrin gelişimine her zaman olumlu yönde katk1 sunacaktır.

Çalışma alanının geneline yayılmış olan orta uygunluk alanları (\%37,29-6665,84 ha.) ulaşım ağlarına yakın, mevcut konut, ticaret ve sanayi alanlarının çevresinde yoğunlaşmaktadır. Bu alanlar Tekirdağ şehrindeki mevcut uygun alanların ilerleyen süreçte dolması ile açılması muhtemel yerleşim alanlarını temsil etmektedir. Doğal ve beşeri açıdan orta uygunluk değerine sahip olan bu alanlar, yüksek uygunluk alanlarından sonra ikinci en uygun alanları oluşturmaktadır ve gelecekte Tekirdağ şehrinin özellikle kuzey, kuzeybatı-güneybatı ve kuzeydoğu yönünde genişleyeceği öngörüsünü desteklemektedir (Harita 11).

Sonuç olarak; bu çalışmada her ne kadar Tekirdağ şehrinin YKA şekline ne zaman geleceği öngörülemese de, özellikle şehrin güneyinde (mevcut yerleşim alanları dâhil) yer alan alçak kıyılar ve kıyının doldurulmasıyla kazanılan alanlarının yerleşime uygun olmadığı bilinmesi gereken bir gerçektir. Diğer taraftan yapılacak bilimsel analizlerin, yeni yerleşim alanlarının açılması sürecinde, doğal çevrenin korunmasında ve yaşanması muhtemel doğal afetlerden minimum ölçüde etkilenilmesinde önemli ölçüde katkı sağlayacağı açıktır. Bu çerçevede, gerçekleştirdiğimiz bu çalışmanın Tekirdağ şehri özelinde çalışma yapacak ilgililere ve karar vericilere yararlı olmasını temenni ediyoruz.

Hakem Değerlendirmesi: Dış bağımsız.

Çıkar Çatıșması: Yazarlar çıkar çatışması bildirmemiştir.

Finansal Destek: Yazarlar bu çalışma için finansal destek almadığını beyan etmiştir.

Peer-review: Externally peer-reviewed.

Conflict of Interest: The authors have no conflict of interest to declare.

Grant Support: The authors declared that this study has received no financial support.

\section{KAYNAKÇA/REFERENCES}

Aydöner, C. ve Maktav, D. (2013). Deprem açısından yerleşim yeri uygunluk analizi. Havacılık ve Uzay Teknolojileri Dergisi, 6(1), 53-62.

Bağdatlı, M. C. (2013). Tekirdă̆ İli Marmara klyı havza karakteristikleri ve taşkın risk faktörlerinin belirlenerek Coğrafi Bilgi Sistemleri (CBS) veri tabanının oluşturulması. (Doktora Tezi). Namık Kemal Üniversitesi, Tekirdağ.

Buzai, G. D. \& Principi, N. (2017). Identification of potential areas of landuse conflict in the Lujan River Basin, Argentina. Revista Geográfica de América Central. $N^{o}$ 59, 125-157. https://www. redalyc.org/jatsRepo/4517/451751862005/html/index.html
Carr, M. H. \& Zwick, P. (2007). Smart land-use analysis: The LUCIS Model. ESRI Press, New York.

Ceylan, M. A. ve Demir, Ş. (2020). Türkiye'de şehir coğrafyası araştırmalarına genel bir bakış. Uluslararası Sosyal Araştırmalar Dergisi, 13(70), 216-241.

Çavuş, C. Z. ve Koç, T. (2015). Çanakkale boğazı doğusunda arazi kullanım uygunluğunun yerleşme açısından analizi. Coğrafi Bilimler Dergisi, CBD 13(1), 41-60.

Dutta, D., Herath, S. ve Musiake, K. (2006). An application of flood risk analysis system for impact analysis of a flood control plan in a river basin. Hydrological Processes, 20(6), 1365-1384.

Göka, Ş., (2001). Insan ve mekân. (1. bs). İstanbul: Pınar Yayınları.

Huang, H., Li, Q. \& Zhang, Y. (2019). Urban residential land suitability analysis combining remote sensing and social sensing data: a case study in Beijing, China. Sustainability, 11(2255), 1-19. https:// www.mdpi.com/2071-1050/11/8/2255

Kavurmac1, M. (2016). Settlement suitability analysis using geographical information system (GIS): A case study in Aksaray, Turkey. J. Int. Environmental Application \& Science, 11(3), 229240. https://dergipark.org.tr/tr/download/article-file/571399

Kurnaz, T. F. ve Ramazanoğlu, Ş. (2014). Yerleşime uygunluğun coğrafi bilgi sistemleri (CBS) ile sorgulanması, Esenler (İstanbul) örneği. SAÜ Fen Bilimler Dergisi, 18, 171-182.

McHarg, I. L. (1992). Design with Nature. John Wiley \& Sons, INC., ISBN: 0-471- 55797-8, USDA.

Nayim, B. N. (2011). Bartın peyzajında alan kullanım uyuşmazlıklarının belirlenmesi: LUCIS modeli. (Doktora Tezi). İstanbul Teknik Üniversitesi Fen Bilimleri Enstitüsü, İstanbul.

Nayim, B. N. (2014). LUCIS modeli ile konut yerleşimine fiziksel açıdan uygun alanların belirlenmesi, Bartın kenti örneği. Bartın Orman Fakültesi Dergisi, 16(23-24), 44-58.

Özçağlar, A. (2014). Coğrafyaya giriş-sistematik, kavramlar, yöntemler. Ümit Ofset, Ankara.

Özügül, M. D. (2004). Ekolojik planlamada kullanılabilecek analitik bir model önerisi. (Doktora Tezi). Yıldız Teknik Üniversitesi Fen Bilimleri Enstitüsü, İstanbul.

Özşahin, E. (2014). CBS kullanılarak şehir ve jeomorfoloji arasındaki ilişkinin incelenmesi: Tekirdağ şehir örneği. I Iğdır Üniversitesi Sosyal Bilimler Dergisi, 6, 93-122.

Özşahin, E. (2015). Şehir ve toprak arasındaki ilişkinin coğrafi yaklaşımla incelenmesi: Tekirdağ şehri örneği. Turkısh Studıes International Periodical for the Languages, Literature and History of Turkish or Turkic, 10(3), 733-758.

Özşahin, E., Pektezel, H. ve Eroğlu, İ. (2016). Tekirdağ şehri ve yakın çevresinde arazi kullanımının zamansal ve mekânsal değişimi. ZfWT, 8(1), 307-326.

Siyavuş, A. E. (2019). Tekirdă̆ şehir coğrafyast. (Doktora Tezi). Marmara Üniversitesi Sosyal Bilimler Enstitüsü, İstanbul.

Steiner, F. R. (2000). The living landscape: An ecological approach to landscape planning. 2 nd Edition, New York: McGraw-Hill Press. 
Tanoğlu, A. (1964). Coğrafya nedir?. İstanbul Üniversitesi Coğrafya Enstitüsü Dergisi, 14, 3-14, İstanbul.

Taşdemir, İ. ve Kaya, Ş. (2015). Yerleşim alanı uygunluk analizi: LUCIS modeli. TUFUAB VIII. Teknik Sempozyumu, 21-23 Mayıs 2015, 146-149, Konya.

Taşdemir, İ. (2017). Düzey II bölgelerinde kalkınma modeli oluşturmada coğrafi bilgi sistemlerinin rolü: LUCIS modeli yaklaşımı. (Doktora Tezi). İstanbul Teknik Üniversitesi Fen Bilimleri Enstitüsü, İstanbul.

Tolun Denker, B. (1973). Tekirdağ şehir nüfusu. İstanbul Üniversitesi Coğrafya Enstitüsü Dergisi, 18-19, 151-166. İstanbul.
Tunçdilek, N. (1986). Türkiye'de yerleşmenin evrimi. İstanbul Üniversitesi, Yayın No: 3367, İstanbul.

Turan, L. (2008). Tekirdağ ilinin taşkın sorunları. V. Dünya Su Formu Bölgesel Su Toplantıları, Taşkın Konferansı Bildiriler Kitabı, 19-20 Haziran, Edirne.

Winterbach H.E.K., Winterbach C.W. \& Somers M. J. (2014). Landscape suitability in Botswana for the conservation of Its Six Large African Carnivores. PLoS ONE, 9(6), 1-12. https://journals.plos.org/ plosone/article/figure?id=10.1371/journal.pone.0100202.g002. 